\title{
Accelerating progress in improving diets and nutrition in Ethiopia
}

Kaleab Baye and Kalle Hirvonen 


\section{CONTENTS}

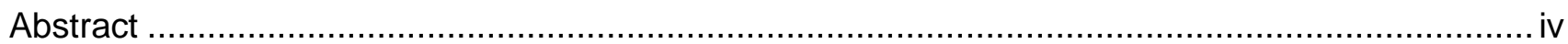

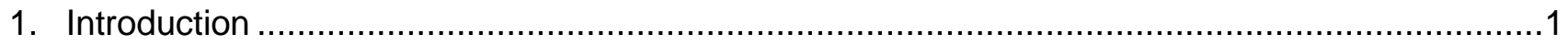

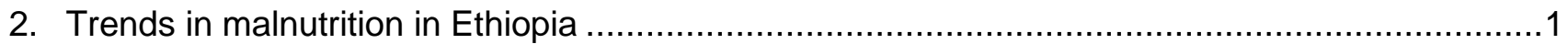

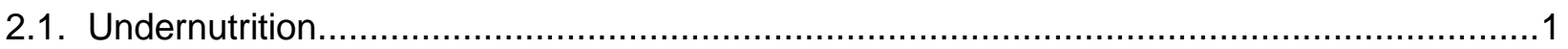

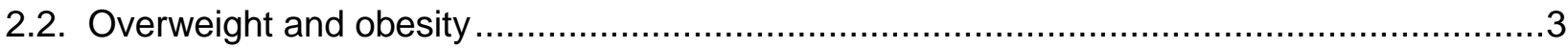

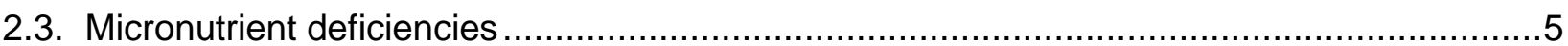

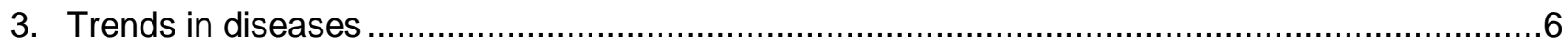

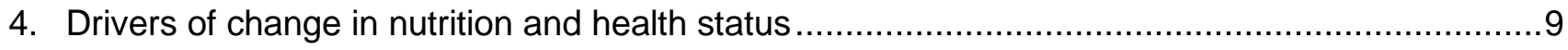

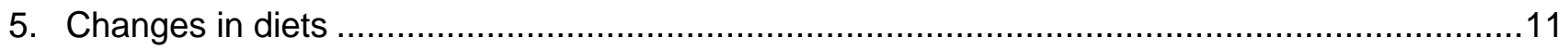

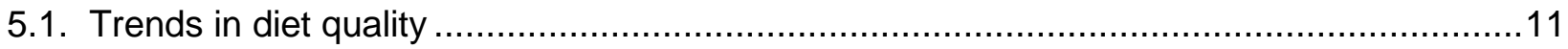

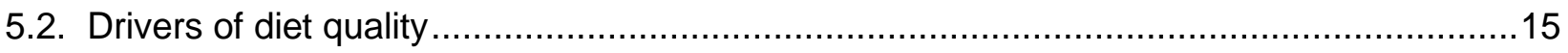

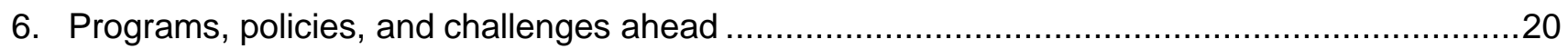

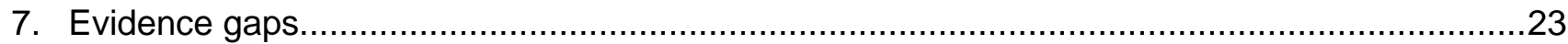

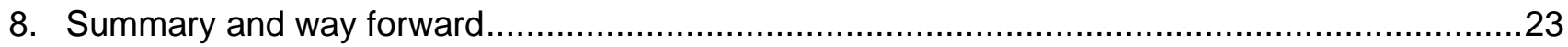

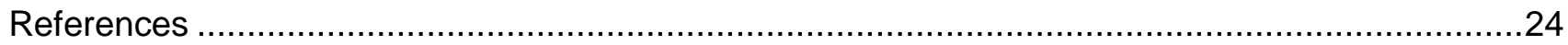

\section{TABLES}

Table 1. Prevalence of overweight and obesity among children aged 6 to 59 months in Ethiopia, 2000 to 2016, percent

Table 2. Anemia prevalence in children, women, and men by rural-urban and wealth quintiles, 2005, 2011, and 2016

\section{FIGURES}

Figure 1. Trends in the prevalence of stunting in children 6 to 59 months of age in Ethiopia by

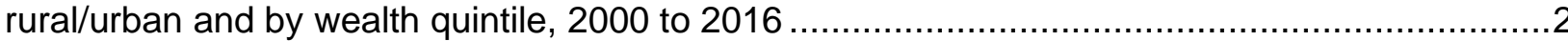

Figure 2. Prevalence of stunting in children 0 to 59 months of age in Ethiopia by child age, 2000 and 2016.

Figure 3. Undernutrition in women, 2000 to 2016, and men, 2011 and 2016, in Ethiopia, by rural/urban.

Figure 4. Prevalence of underweight in women and men, respectively, by age in rural Ethiopia, 2000 and 2016

Figure 5. Prevalence of overweight and obesity in women and men, respectively, by age in urban Ethiopia, 2000 and 2016

Figure 6. Prevalence of overweight and obesity in women, 2000 to 2016, and men, 2011 and 2016, in Ethiopia, by rural/urban

Figure 7. Age-standardized causes of death in Ethiopia, by rank, 1990 and 2017 ....................6

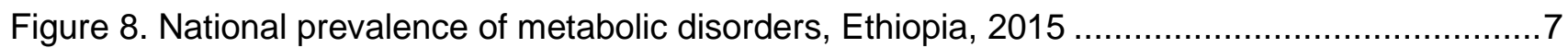

Figure 9. Neonatal and child mortality in Ethiopia, 1990 to 2019 .............................................. 7

Figure 10. Estimates of deaths prevented in children under five years of age in Ethiopia through

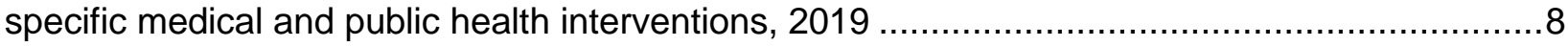

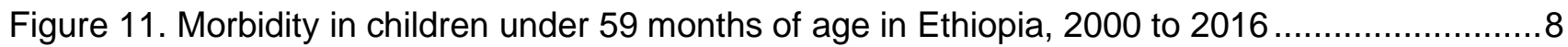

Figure 12. Diarrhea morbidity in children under five years of age, by age in months, 2000 and 20169 
Figure 13. Household access to water, sanitation and hygiene (WASH) services in Ethiopia, 2000 and 2017.

Figure 14. Estimates of prevention of stunting in children under five years of age in Ethiopia through specific public health interventions, 2019

Figure 15. Summary of risk factors related to communicable and non-communicable diseases in Ethiopia.

Figure 16. Exclusive breastfeeding by young child's age in months, 2000 and 2016, percentage share of infants.

Figure 17. Number of food groups reported consumed by children aged 6 to 23 months in 2011 and 2016 (left) and in rural and urban Ethiopia (right), by age of child,

Figure 18. Children aged 6 to 23 months meeting the minimum dietary diversity standard, by wealth quintile, 2011 and 2016

Figure 19. Adults in Ethiopia meeting recommendation of World Health Organization of five servings daily of fruit or vegetables, by region, 2015

Figure 20. Average salt intake by the adult population of Ethiopia, by region, $2015 \ldots \ldots \ldots \ldots \ldots \ldots \ldots 14$

Figure 21. Conceptual framework linking food systems to diet quality.................................... 15

Figure 22. Exposure of Productive Safety Net Programme households to nutrition messages from Health Extension Workers, March 2019 and August 2019, by region ....

Figure 23. Composite coverage index in Ethiopia of essential reproductive, maternal, newborn, and child health interventions, by household wealth quintile ................................................. 17

Figure 24. Health extension workers time allocation by health package ....................................17

Figure 25. Agricultural production in Ethiopia, by major food groups, 2011 to 2015 .....................18

Figure 26. Agricultural production diversity, 2011-15........................................................ 19

Figure 27. Map showing rainfall pattern across Ethiopia and sites with irrigation potential .............19

Figure 28. Selected policies and programs of the government of Ethiopia related to nutrition .........20

\section{TEXT BOXES}

Text Box 1. Pillars of the Food and Nutrition Policy for Ethiopia.

Text Box 2. Possible policy and programmatic reforms for improving diets and nutrition in Ethiopia21 


\section{ABSTRACT}

Ethiopia has witnessed significant reductions in child mortality, undernutrition, and communicable diseases, but more substantial and faster progress is still needed. The rise in obesity and in noncommunicable diseases, particularly in urban areas, is alarming and requires urgent policy and programmatic attention. Unhealthy diets drive both undernutrition and obesity and are the underlying cause of significant proportion of both communicable and non-communicable diseases. Maintaining the relatively high breastfeeding practices and increasing the diversity of diets will be critical to improving nutrition in Ethiopia. Implementation of effective nutrition messaging that shapes consumer behavior to adopt healthy dietary patterns, while bridging gaps in both the reach and the quality of such messaging is warranted. The health extension program, which is the cornerstone of the transformation of the health sector, may need to be redesigned in a way that improves its reach and the quality of the services it provides and minimizes the risk of burnout of frontline health workers. Interventions focusing on making healthy diets available, affordable, and accessible are urgently needed. 


\section{INTRODUCTION}

Malnutrition in all its forms affects a third of the world population and has become the leading risk factor for the global burden of disease (Hawkes \& Fanzo 2017). Low and middle income countries have always been disproportionately affected by undernutrition. However, in recent years the rise in the prevalence of overweight and obesity has exacerbated the nutrition problem, stretching health systems (Pradeilles et al. 2019; WHO 2017). Poverty, poor diets, and low physical activity are some of the social determinants of malnutrition (Perez-Escamilla et al. 2018). Understanding how these factors interact is critical for the design of policies and programs that can accelerate progress in addressing all forms of malnutrition.

Over the past 20 years, Ethiopia has witnessed remarkable economic growth, a rise in agricultural productivity, and a mainstreamed nutrition agenda to catalyze improvements in the nutrition and health status of its citizens. Although the prevalence of undernutrition and communicable diseases remains unacceptably high, the country has recorded one of the fastest reductions in child undernutrition and child mortality globally over the past two decades (Golan et al. 2019; Ruducha et al. 2017). However, the nutrition landscape is rapidly evolving with an increasing burden from overweight and obesity and related non-communicable diseases (Misganaw et al. 2014). Understanding these dynamics and identifying drivers of change in the past decades is critical to identify missed opportunities that, if addressed, can accelerate progress towards Ethiopia meeting the nutrition-related Sustainable Development Goals (SDGs).

Ethiopia is entering a new development planning phase for the next 5 year and 10 year periods, the ends of which will coincide with the deadlines of the UN Decade of Action on Nutrition (2025) and the SDGs (2030). This paper aims to inform this planning cycle and subsequent interventions by providing a synthesis of evidence on the trends and drivers of nutritional status and disease burden in Ethiopia. Through a review of published scientific articles, program reports, and policy documents, we document lessons learnt and attempt to provide foresight and policy relevant recommendations. The UNICEF conceptual framework linking nutritional status to immediate drivers (i.e. diets and diseases) and the framework of the Global Panel on Agriculture and Food Systems for Nutrition (GLOPAN) that links diet quality to food systems are used to frame this review of the evidence (Scott 2017; UNICEF 1990).

The paper is primarily targeted to provide evidence to stakeholders involved in nutrition policy and programming. Nonetheless, it may be of a wider interest to researchers in nutrition or closely related fields. The paper focuses on interventions to prevent malnutrition, so does not address emergency or clinical-nutrition interventions. The paper begins by documenting the trends in child and adult malnutrition in Ethiopia over past decades. Section 3 provides an overview of the prevalence of communicable and non-communicable diseases in the country. Section 4 synthesizes the existing literature on the drivers of changes in nutrition and health in Ethiopia and identifies poor dietary quality as a common risk factor. Motivated by this, in Section 5 , we more closely examine child and adult diets and the factors shaping them. In Section 6, we provide a brief overview of the prevailing policy and program landscape in Ethiopia and the challenges ahead. Section 7 outlines the evidence gaps, while Section 8 summarizes.

\section{TRENDS IN MALNUTRITION IN ETHIOPIA}

\subsection{Undernutrition}

Child stunting, a measure of chronic undernutrition, declined from 58 percent in 2000 to 38 percent in 2016 (Figure 1, left). Faster stunting reductions were observed among urban residents and the 
wealthiest quintile (Figure 1, right), a pattern also seen in many other African countries (Baye et al. 2020; Golan et al. 2019). Stunting prevalence in 2016 was much lower than in 2000 across all age groups between 0 and 59 months. However, reductions in stunting prevalence were more pronounced among children in their first six months of age than later in childhood (Figure 2). This could be due to the considerable improvements in exclusive breastfeeding prevalence over this period (Golan et al. 2019).

Figure 1. Trends in the prevalence of stunting in children 6 to 59 months of age in Ethiopia by rural/urban and by wealth quintile, 2000 to 2016
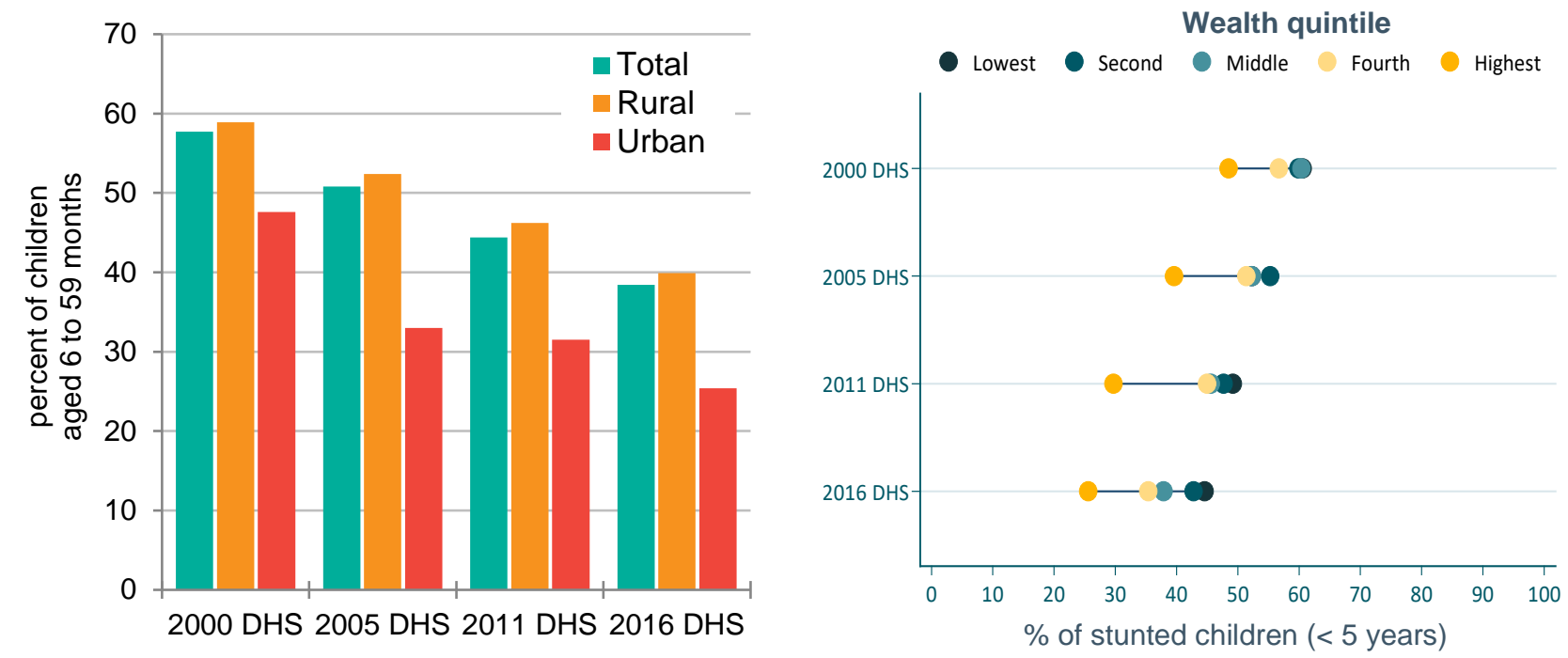

Source: Authors' analysis of Ethiopia Demographic and Health Surveys.

Figure 2. Prevalence of stunting in children 0 to 59 months of age in Ethiopia by child age, 2000 and 2016

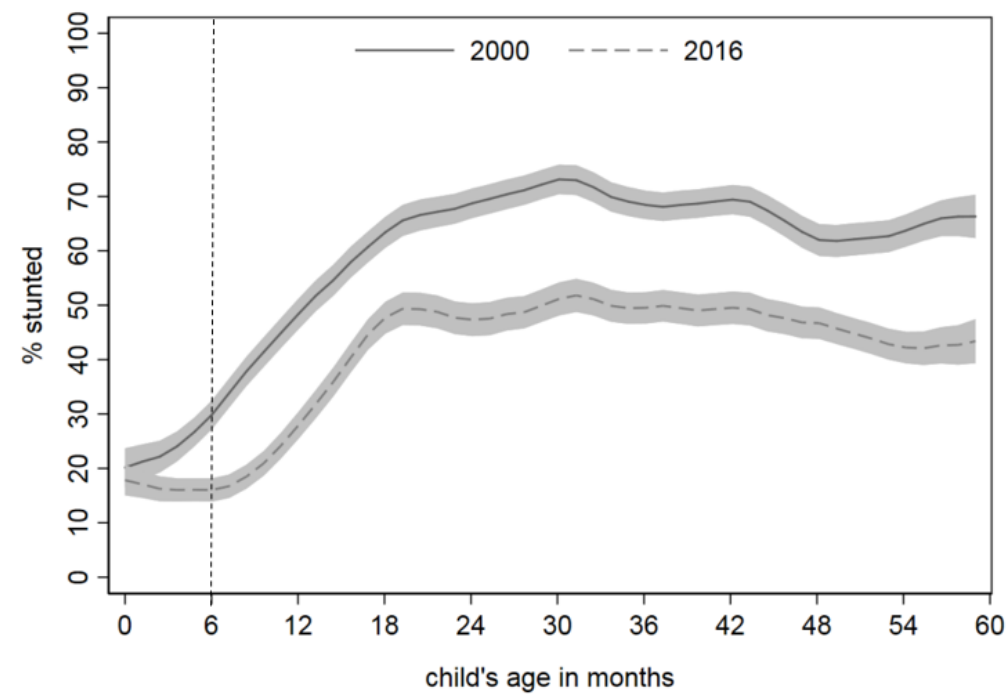

Source: Authors' analysis of Ethiopia Demographic and Health Surveys.

Note: Shaded area around each plot is the $95 \%$ confidence interval on the estimates.

Similar to trends seen in children, adult undernutrition prevalence based on a body mass index (BMI) of less than $18.5 \mathrm{~kg} / \mathrm{m}^{2}$, considerably declined between 2000 and 2016 (Figure 3). Still, 15 percent of women in urban centers and 25 percent in rural settings were undernourished in 2016. Noteworthy is the high prevalence of undernutrition in men in both rural and urban Ethiopia in 2016, 34 percent of men in rural and 26 percent in urban areas were undernourished. This is an important finding because existing nutrition interventions rarely target men. 
Figure 3. Undernutrition in women, 2000 to 2016, and men, 2011 and 2016, in Ethiopia, by rural/urban
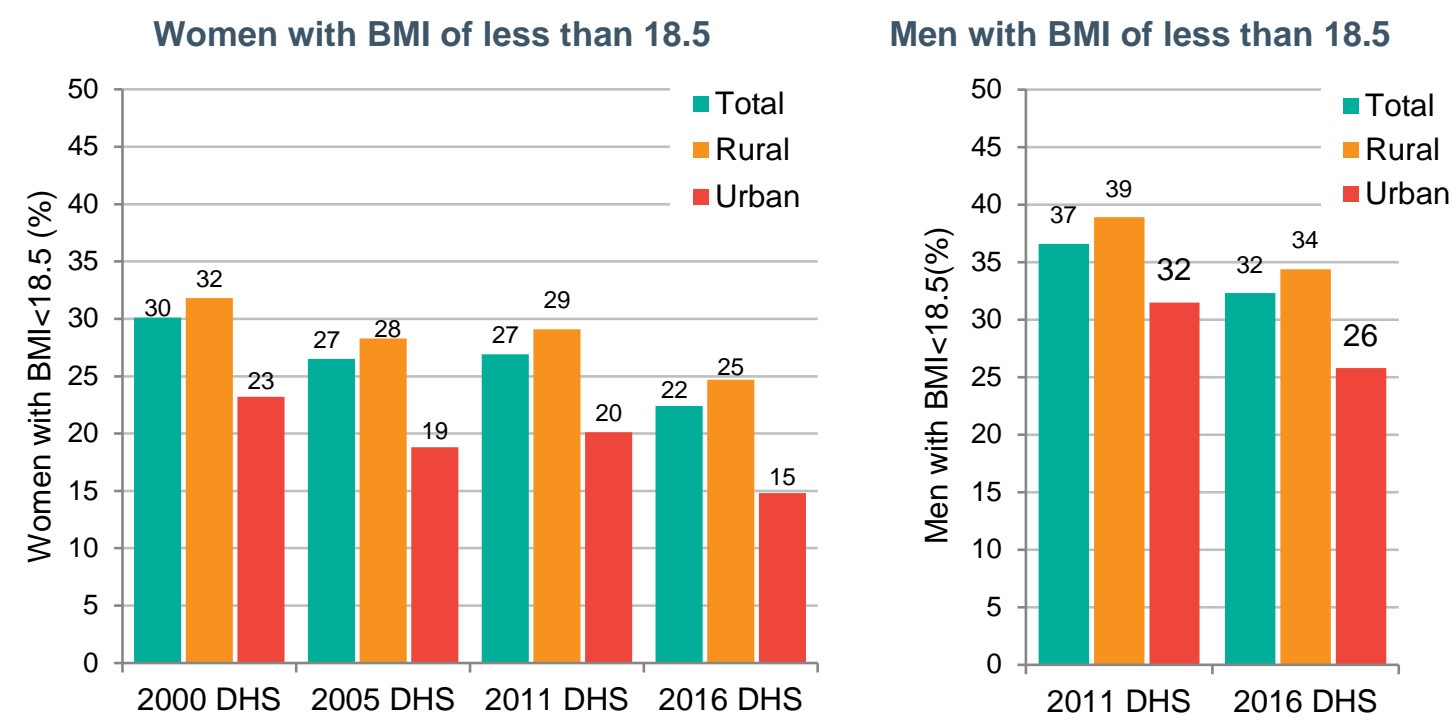

Source: Authors' analysis of Ethiopia Demographic and Health Surveys.

A closer look at the prevalence of undernutrition by age shows that undernutrition is high among adolescents and rapidly declines to plateau around 20 percent for women and 30 percent for men at around age 19 years (Figure 4). ${ }^{1}$ This highlights the need for more forceful and expanded interventions to address undernutrition during adolescence.

Figure 4. Prevalence of underweight in women and men, respectively, by age in rural

Ethiopia, 2000 and 2016
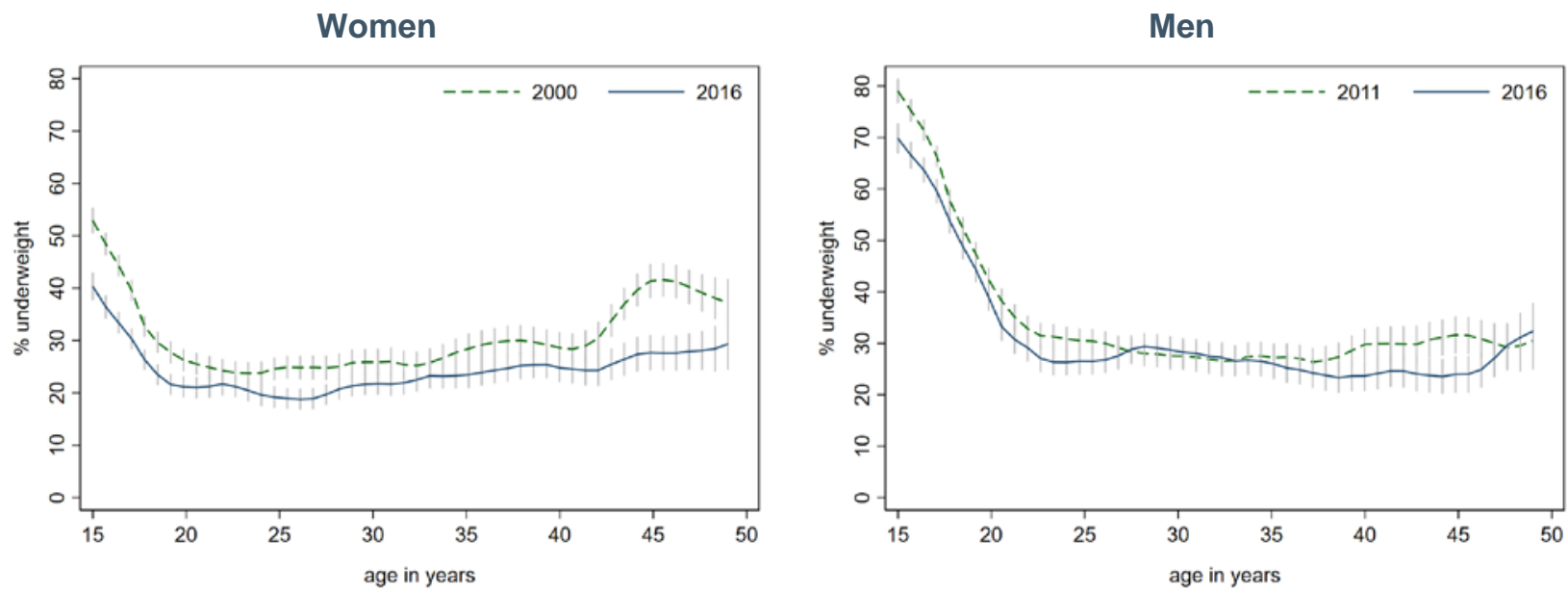

Source: Authors' analyses of the DHS

\subsection{Overweight and obesity}

The prevalence of overweight and obesity in children has remained low at less than 5 percent and stable over the period between 2000 and 2016, with no significant difference between boys and girls or between rural and urban (Table 1).

${ }^{1}$ A caveat here is that adolescents are still growing in stature and therefore changes in BMI could arise from changes in weight or height. Therefore, caution is warranted when we compare the adolescent BMI to adult BMI. Nevertheless, the adolescent BMI trends suggest that adolescent girls are not receiving enough energy and nutrients to support their growth. 
Table 1. Prevalence of overweight and obesity among children aged 6 to 59 months in Ethiopia, 2000 to 2016, percent

\begin{tabular}{lr|rrrr} 
Year & Total & Male & Female & Urban & Rural \\
2016 & 3.6 & 3.5 & 3.7 & 3.5 & 3.6 \\
2011 & 1.7 & 1.5 & 1.9 & 3.3 & 1.5 \\
2005 & 4.0 & 4.4 & 3.6 & 5.4 & 3.9 \\
2000 & 1.8 & 1.8 & 1.8 & 2.8 & 1.7 \\
\hline
\end{tabular}

Source: authors' analyses of the DHS

However, the relatively high prevalence of overweight and obesity among adolescent girls in 2016, particularly in urban settings (Figure 5), indicates the need to pay attention to this trend and implement interventions that prevent it from rising further in years to come. The prevalence of overweight in urban adolescent boys has remained at less than 5 percent. However, in the years after adolescence, the prevalence rate for overweight and obesity among males rises sharply.

Figure 5. Prevalence of overweight and obesity in women and men, respectively, by age in urban Ethiopia, 2000 and 2016
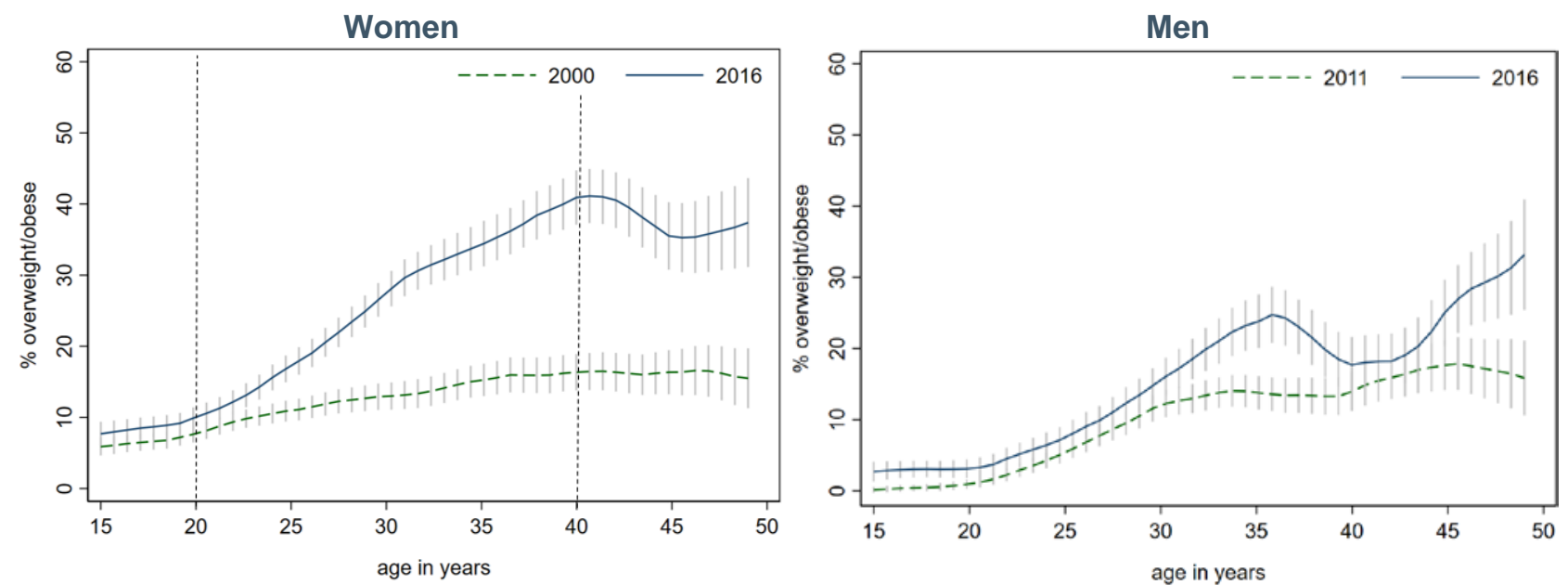

Source: Authors' analyses of the DHS

On the other hand, the adult overweight and obesity figures depicts a rather different picture (Figure 6). A rise of over 6 percentage points in the prevalence rate among urban women was witnessed between 2011 and 2016. During the same period, the prevalence rate among urban men increased by just under 5 percentage points. A closer look at the overweight and obesity prevalence by age for women reveals a linear increase with age between 20 and 40 years of age, followed by a slight decline afterwards (Figure 5).

The prevalence of obesity (BMI of 30.0 or higher) has been increasing, particularly among the urban population. Among urban men, the prevalence of obesity increased slightly between 2011 and 2016 to 1.7 percent, while during the same period, a much more substantial increase was observed in urban women, rising from 1.5 to 5.6 percent. For both men and women, the highest wealth quintile was disproportionately affected by overweight and obesity (CSA \& ICF 2017).

Both the trends in overweight and undernutrition illustrate that adolescence is a window of opportunity to catalyze improvements in nutrition. Currently, the sole nutritional intervention targeted at adolescents in Ethiopia is iron-folic acid supplementation, which only targets girls. Although this is an important intervention, it is not sufficient and does not address both forms of malnutrition. It will be critical to expand the set of interventions that address the shared drivers of both forms of malnutrition during adolescence and expand interventions to reach boys as well. 
Figure 6. Prevalence of overweight and obesity in women, 2000 to 2016, and men, 2011 and 2016, in Ethiopia, by rural/urban

Women with BMI greater than 25.0

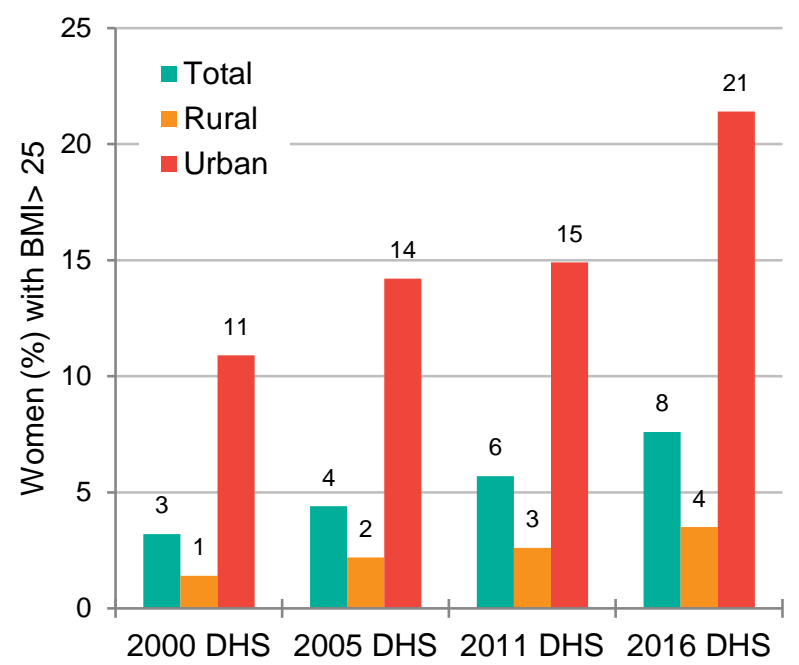

Men with BMI greater than 25.0

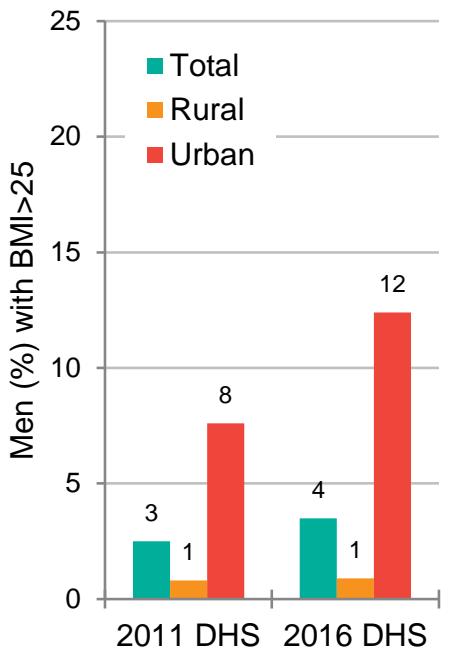

Source: Authors' analysis of Ethiopia Demographic and Health Surveys.

How to best implement interventions targeted at adolescents in urban settings, such as nutritional supplementation or dietary intake behavior changes, remains largely unknown (Canavan \& Fawzi 2019). Integrating adolescent nutrition through school feeding platforms and sexual and reproductive health strategies presents opportunities for improving adolescent nutrition and health (Berhane et al. 2019).

The combination of a high prevalence of undernutrition and rapidly rising rates of overweight and obesity in urban areas is alarming and can have serious implications on the burden of disease. Health policies in Ethiopia need to be reworked to integrate double-duty actions to address all forms of malnutrition simultaneously (Hawkes et al. 2019). Failing to do so will further burden the already weak health system.

\subsection{Micronutrient deficiencies}

Although several small scale studies have evaluated the micronutrient status of Ethiopians, the Ethiopian National Micronutrient Survey is unique in being nationally representative and in evaluating several micronutrients at the same time (EPHI 2016). The survey showed that, based on WHO cut-offs, suboptimal vitamin A, iodine, and zinc status are significant public health concerns in Ethiopia (EPHI 2016). Anemia is highly prevalent among children aged under five years, rural residents, and those in the lowest wealth quintile (Table 2).

Significant regional variations in anemia are observed. For example, the prevalence of anemia in women is 16 percent in Addis Ababa and 17 percent in Amhara, but 60 percent in Somali region. In children, the prevalence of anemia in Somali is almost twice that in Amhara.

The etiology of anemia is complex and can be related to nutritional deficiencies, e.g., iron deficiency; inflammation or infection; and genetic hemoglobin disorders (Chaparro \& Suchdev 2019). Despite predominantly plant-based diets in Ethiopia, the prevalence of iron deficiency is surprisingly low, even among vulnerable groups such as children and women of reproductive age (Baye 2019a; EPHI 2016). The low prevalence of iron deficiency reported by the National Micronutrient Survey is in line with earlier smaller scale studies (Gashu et al. 2016; Seyoum et al. 2019). It is also in agreement with the findings of high and excessive iron intake in the National Food Consumption Survey (EPHI 2013). The primary sources of the high iron intake were staple foods and additional extrinsic iron due to soil contamination (Baye et al. 2014). Although the 
bioavailability of this extrinsic iron has been questioned, a more recent study using an animal model suggested that contaminant, i.e., extrinsic, iron could contribute to hemoglobin regeneration and thus is potentially bioavailable (Guja \& Baye 2018). On the other hand, the high prevalence of inflammation among children under five years of age (44 percent), school children (32 percent), and non-pregnant women (27 percent) further complicates the interpretation of micronutrient biomarkers, but also contributes to anemia prevalence (EPHI 2016). Another factor that can lead to anemia relates to genetic abnormalities, like ß-thalassemia, but studies to assess its prevalence in Ethiopia do not exist yet.

Table 2. Anemia prevalence in children, women, and men by rural-urban and wealth quintiles, 2005, 2011, and 2016

\begin{tabular}{|c|c|c|c|c|c|c|c|c|}
\hline \multirow[b]{2}{*}{ Year } & \multirow[b]{2}{*}{ Total } & \multicolumn{2}{|c|}{ Residence } & \multicolumn{5}{|c|}{ Wealth Quintile } \\
\hline & & Urban & Rural & Lowest & Second & Middle & Fourth & Highest \\
\hline \multicolumn{9}{|c|}{ Children } \\
\hline 2016 & 56.9 & 49.3 & 57.8 & 67.8 & 57.6 & 52.6 & 54.0 & 47.9 \\
\hline 2011 & 44.2 & 35.2 & 45.4 & 47.9 & 47.6 & 43.3 & 43.1 & 35.9 \\
\hline 2005 & 53.5 & 46.8 & 54.0 & 59.9 & 55.7 & 52.8 & 49.1 & 47.8 \\
\hline \multicolumn{9}{|c|}{ Women } \\
\hline 2016 & 23.6 & 17.0 & 25.4 & 34.3 & 25.3 & 23.7 & 21.0 & 17.4 \\
\hline 2011 & 16.6 & 10.9 & 18.3 & 20.1 & 18.9 & 17.1 & 17.4 & 11.3 \\
\hline 2005 & 26.6 & 17.8 & 28.2 & 31.8 & 30.3 & 26.7 & 28.5 & 17.4 \\
\hline \multicolumn{9}{|c|}{ Men } \\
\hline 2016 & 15.0 & 14.5 & 7.2 & 16.2 & 22.4 & 17.4 & 15.2 & 13.0 \\
\hline 2011 & 12.0 & 11.3 & 4.8 & 13.1 & 16.2 & 15.5 & 12.8 & 9.6 \\
\hline
\end{tabular}

Source: Authors' analysis of Ethiopia Demographic and Health Surveys.

\section{TRENDS IN DISEASES}

In 1990, four out of the top ten causes of agestandardized deaths in Ethiopia were from communicable diseases (Figure 7). However, in 2017 only two of the top ten causes of death were from communicable diseases. A 65 percent reduction in the risk of death from communicable diseases occurred between 1990 and 2015 (Misganaw et al. 2017). A comparison of cause of death by sex reveals similar trends, except for diabetes and chronic kidney disease being ranked 5th in 2017 in women and 6th in men.

The rising risk of death from non-communicable diseases, such as cardiovascular diseases, is in line with the findings of the WHO STEPwise approach to surveillance (STEPS) survey that reported high prevalence of associated risk factors, such as hypertension and metabolic disorders (Figure 8) (Gebreyes et al. 2018).
Figure 7. Age-standardized causes of death in Ethiopia, by rank, 1990 and 2017

\begin{tabular}{|c|c|}
\hline 1990 rank & 2017 rank \\
\hline 1. Respiratory infections and TB & 1. Cardiovascular diseases \\
\hline 2. Cardiovascular diseases & 2. Respiratory infections \& TB \\
\hline 3. NTDs \& malaria & 3. Neoplasms, including cancer \\
\hline 4. Enteric infections, including diarrhea & 4. Enteric infections, including diarrhea \\
\hline 5. Other infections & 5. Digestive diseases \\
\hline 6. Neoplasms, including cancer & 6. Diabetes \& CKD \\
\hline 7. Maternal and neonatal & 7. Maternal \& neonatal \\
\hline 8. Diabetes \& CKD & 8. Neurological disorders \\
\hline 9. Digestive diseases & 9. Chronic respiratory \\
\hline 10. Self-harm \& violence & 10. Unintentional injury \\
\hline
\end{tabular}

Maternal, neonatal, and nutrition-related Non-communicable diseases

Communicable diseases Injuries

Source: IHME, Global burden of disease 2017 (adapted)

NTD = neglected tropical diseases; $T B=$ tuberculosis; $C K D=$ chronic kidney disease 
Figure 8. National prevalence of metabolic disorders, Ethiopia, 2015

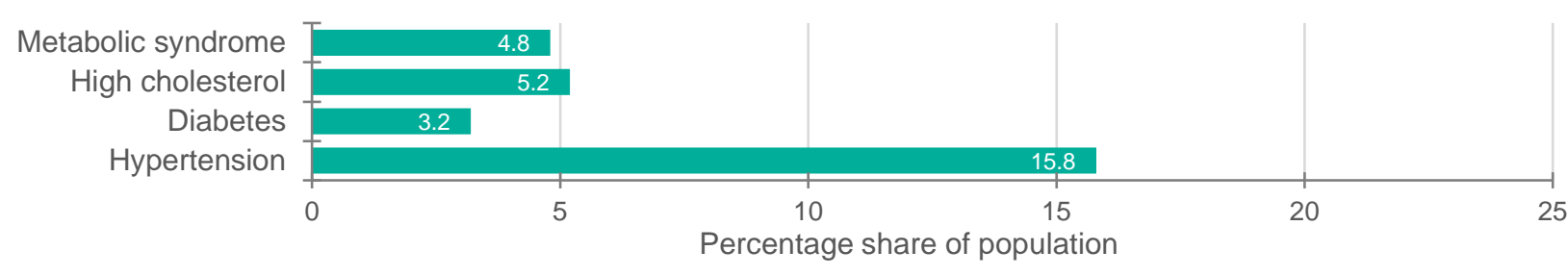

Source: Adapted from Gebreyes et al. 2018

Of note is the remarkable reduction in child mortality between 1990 and 2015, which made Ethiopia among the early achievers of Millennium Development Goal 4 (Ruducha et al. 2017). These reductions in child mortality have been sustained, falling to a rate of 55 per thousand live births in 2019 (Figure 9). The drop in child mortality is partly associated with the reductions in communicable diseases, which could be partly attributed to improvements in the health system (Bilal et al. 2011; Doherty et al. 2016).

Figure 9. Neonatal and child mortality in Ethiopia, 1990 to 2019

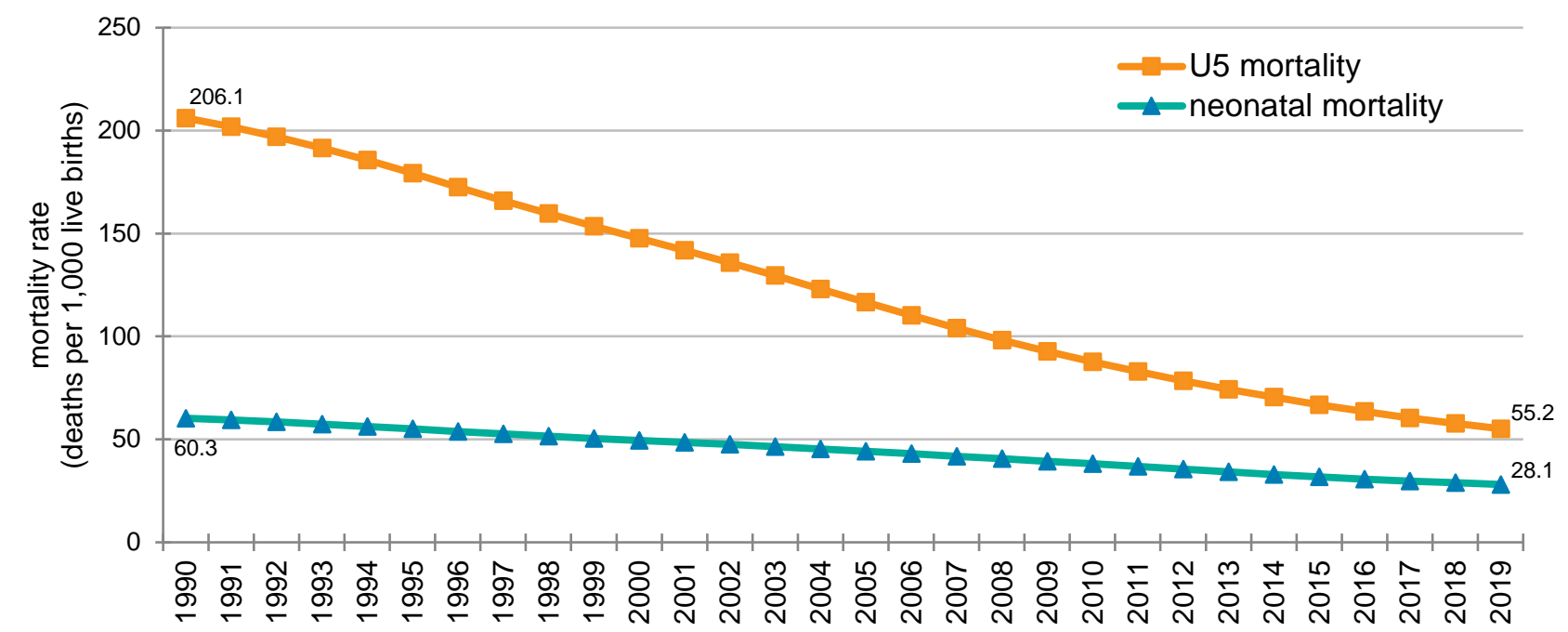

Source: Estimates generated by the UN Inter-agency Group for Child Mortality Estimation (UN IGME) in 2019

However, further reductions in preventable child deaths are still possible and are needed to achieve the SDG targets of neonatal (12 deaths/1000) and under-five mortality (25 deaths/1000) rates. Using the Lives Saved Tool (LiST), we highlight that effective scale-up (90 percent coverage) of treatments of infections, diarrhea, and malnutrition can avert a significant proportion of child deaths (Figure 10). 
Figure 10. Estimates of deaths prevented in children under five years of age in Ethiopia through specific medical and public health interventions, 2019

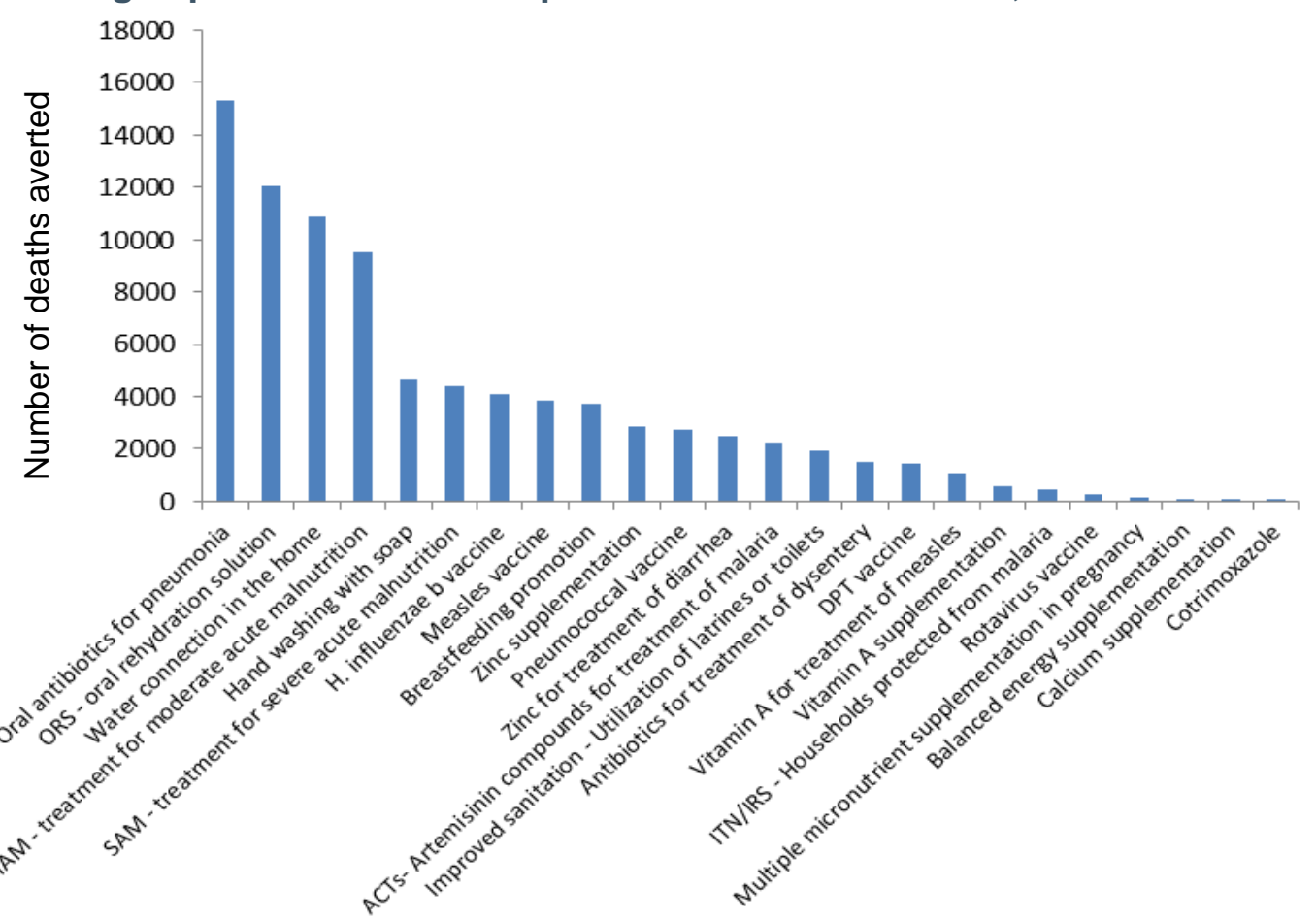

Source: Authors' estimation using the Lives Saved Tool (LiST).

Note: Scale-up is defined as 90 percent coverage, which is often considered as a cut-off for near universal coverage.

While child survival is a top priority, it is also critical for children to be healthy. Using DHS data, morbidity figures for fever, diarrhea, and acute respiratory illness (ARI) in the two weeks preceding each survey declined between 2000 and 2016 (Figure 11). However, considering the cross-

sectional nature of the DHS surveys and the relatively short periods of recall (two weeks), the 2016 morbidity figures are still alarmingly high. The 2016 morbidity figures were not significantly different by rural/urban residence or wealth quintile (CSA \& ICF 2017).

Figure 11. Morbidity in children under 59 months of age in Ethiopia, 2000 to 2016

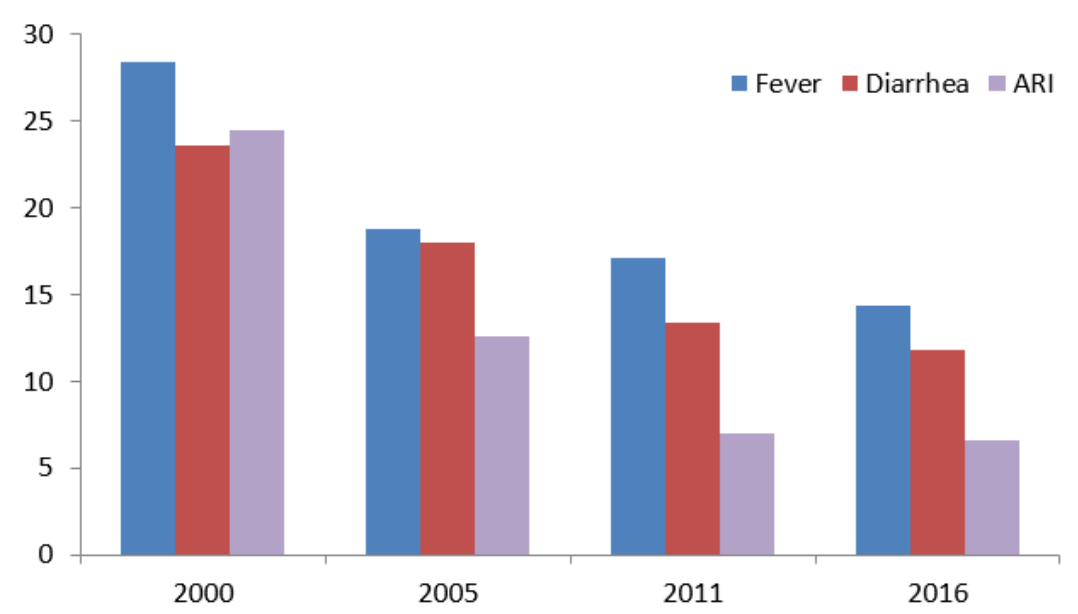

Source: Authors' analysis of Ethiopia Demographic and Health Surveys. ARI = acute respiratory illness.

Reductions in the prevalence of diarrhea are seen over the first five years of life (Figure 12). Diarrhea is not common in the first months after birth, which can be partly attributed to improved breastfeeding practices and improved WASH, particularly reductions in open defecation (Figure 13). Although infants in the first six months of age are not directly in contact with the outside environment, their older siblings and their caregivers are. Hence, the risk of diarrhea increases with 
age, particularly for infants that are not exclusively breastfed in the first six months of life. Indeed, the peak in diarrheal morbidity occurs in the child's second six months of age, from ages 7 to 12 months. This confirms the increased risk of diarrhea with the introduction of complementary foods due to the poor quality of those foods, partly compromised by poor WASH conditions Given that about 40 percent of households have no hygiene facilities, 63 percent rely on unimproved toilet facilities, and about half of households rely on unimproved water sources, much more work is needed to increase coverage of basic WASH services across Ethiopia.

Figure 12. Diarrhea morbidity in children under five years of age, by age in months, 2000 and 2016

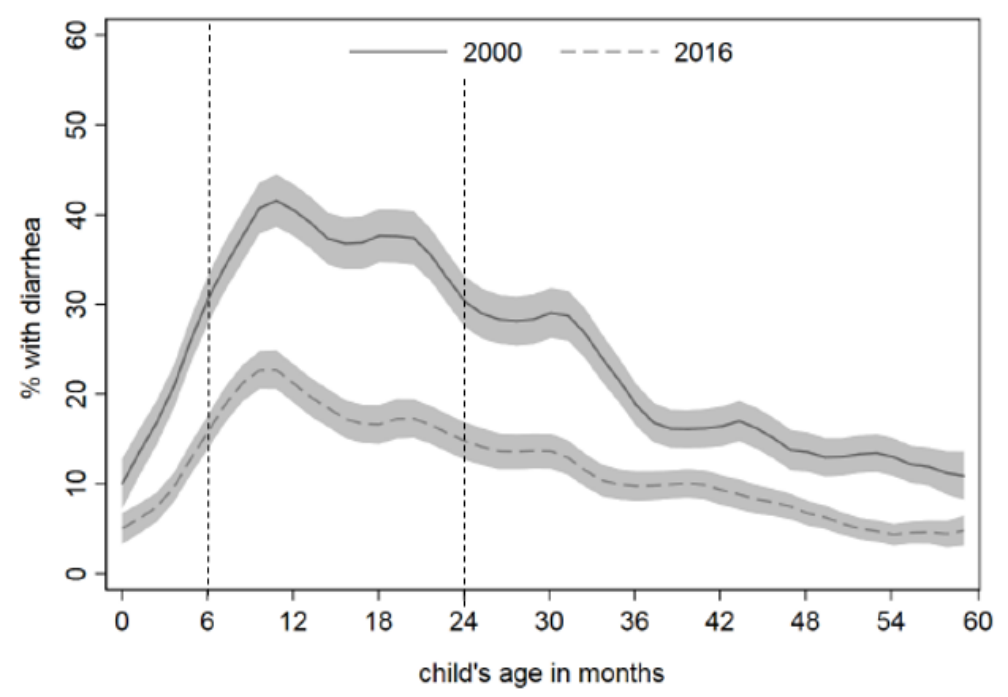

Source: Authors' analysis of Ethiopia Demographic and Health Surveys.

Figure 13. Household access to water, sanitation and hygiene (WASH) services in Ethiopia, 2000 and 2017

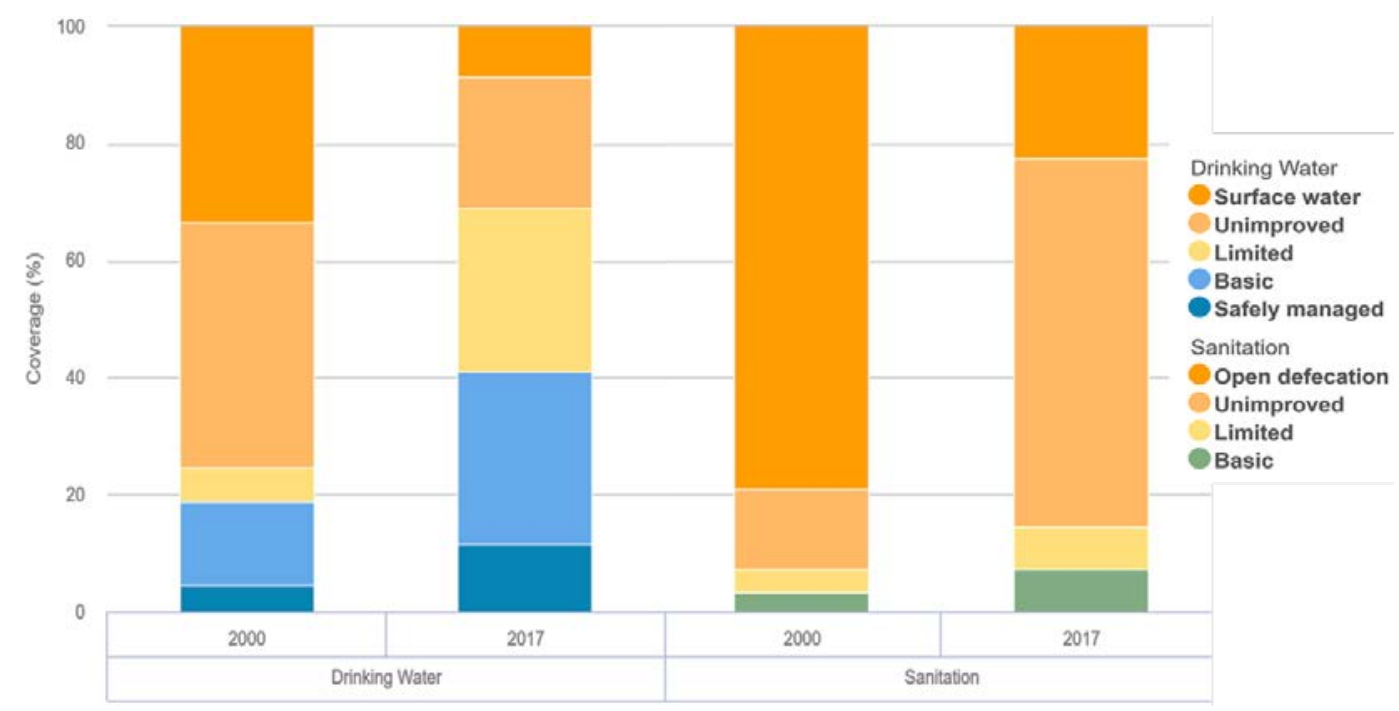

Source: WHO UNICEF JMP (2017).

\section{DRIVERS OF CHANGE IN NUTRITION AND HEALTH STATUS}

Understanding what has led to nutrition and disease trends in Ethiopia is paramount to inform future programming. Careful analysis of the timing of growth faltering over the years suggests that 
improvements in exclusive breastfeeding practices have delayed the onset of stunting (Golan et al. 2019). Moreover, regression decomposition studies, with the caveat of not being able to explain a large part of the stunting reduction, have shown that improvements in wealth, sanitation, maternal education, and access to antenatal care have been important drivers of stunting reduction over the past decade or so (Headey et al. 2017b). Indeed, the rapid economic growth that Ethiopia has witnessed over the last two decades was accompanied by improvements in living conditions, while uneven between urban centers and rural communities that are reflected in the reductions of undernutrition (Hirvonen 2017). Among key drivers of improvements in nutrition and health status include improvements of WASH, particularly the reduction in open defecation.

The introduction of the Health Extension Programme significantly increased access to and coverage of essential health and nutrition services (Lemma \& Matji 2013; Ruducha et al. 2017). This program has partly contributed to the reduction of child mortality and stunting. However, coverage of essential health care and nutrition interventions remain unevenly distributed by ruralurban and wealth quintile, with urban and wealthiest quintile households having significantly better coverage.

A more recent analyses using the Lives Saved Tool (LiST) illustrates that improving the quality of complementary diets, if scaled-up to close to universal coverage levels, would avert the highest number of stunting cases in children (Figure 14) (Baye 2019). Similarly, poor diets contribute to the adverse nutrition and diseases patterns in adults. Poor diets along with physical inactivity were found to be major underlying causes of overweight and obesity and the associated rise in noncommunicable diseases (Melaku et al. 2016). Dietary behaviors, such as low consumption of fruit and vegetables and high salt intake, were the largest contributors to the burden of noncommunicable diseases in Ethiopia. Almost a quarter of deaths due to non-communicable diseases were diet-related (Melaku et al. 2016).

Figure 14. Estimates of prevention of stunting in children under five years of age in Ethiopia through specific public health interventions, 2019

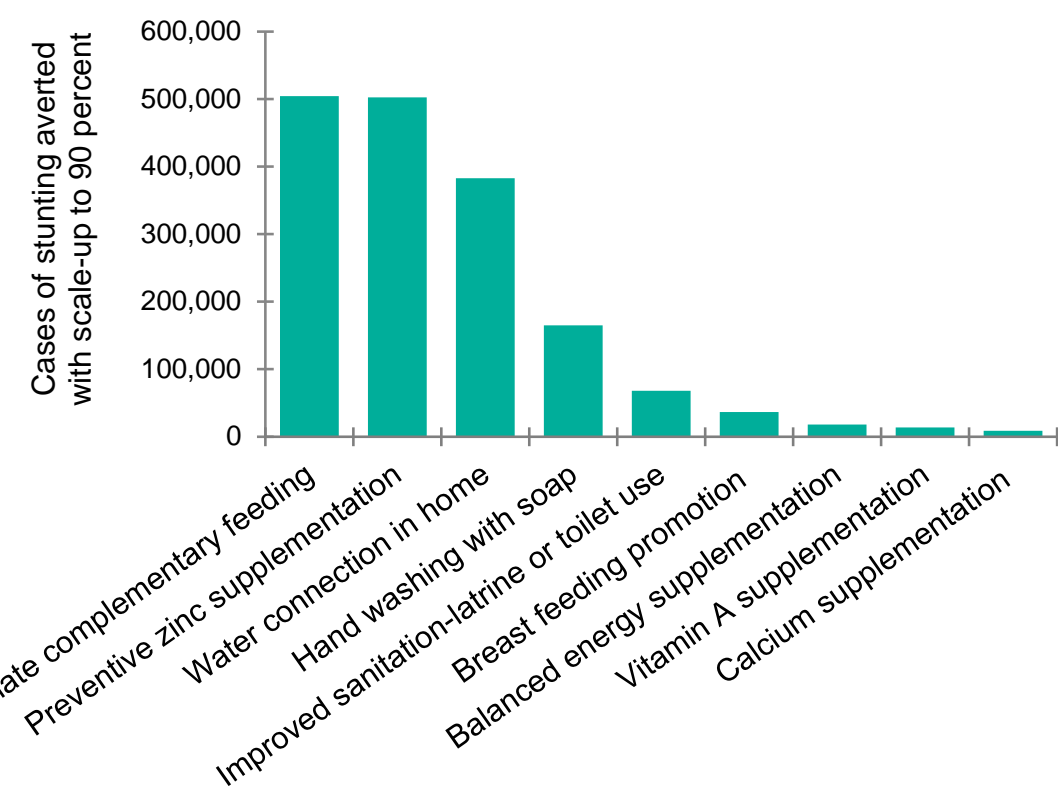

Source: Baye (2019)

In summary, rural residence, poor access to WASH facilities, young age, access to health care, and undernutrition have been found to be the leading risk factors found to be associated with communicable diseases in Ethiopia (Figure 15). On the other hand, urban residence, low physical activity, older age, and overweight and obesity are associated with non-communicable diseases. Unhealthy diets were not only the shared drivers for both undernutrition and overweight and 
obesity, but also a common risk factor for both communicable and non-communicable diseases. Together, this suggests that improving diet quality should be at the forefront of the fight against all forms of malnutrition in Ethiopia.

Figure 15. Summary of risk factors related to communicable and non-communicable diseases in Ethiopia

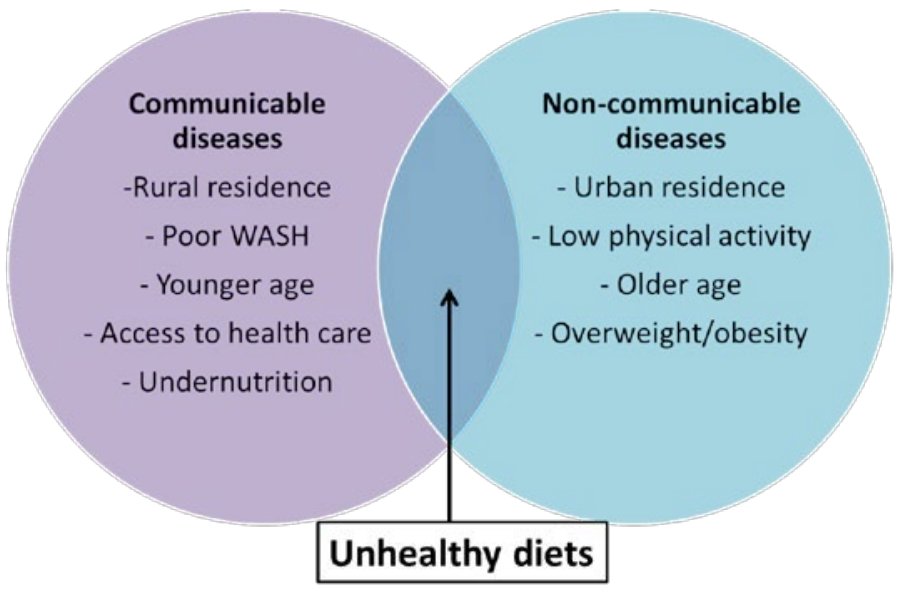

Source: Authors.

\section{CHANGES IN DIETS}

\subsection{Trends in diet quality}

Improving diet quality starts with exclusive breastfeeding during the first six months of life. During this period, breast milk provides all the required nutrients to support healthy growth and development in the infant. After 6 months, children need to be introduced to complementary foods in addition to breast milk. These foods should be provided frequently, because children's gastric capacity is small, and should be nutrient-rich to meet all of the child's nutrient requirements.

Figure 16. Exclusive breastfeeding by young child's age in months, 2000 and 2016, percentage share of infants

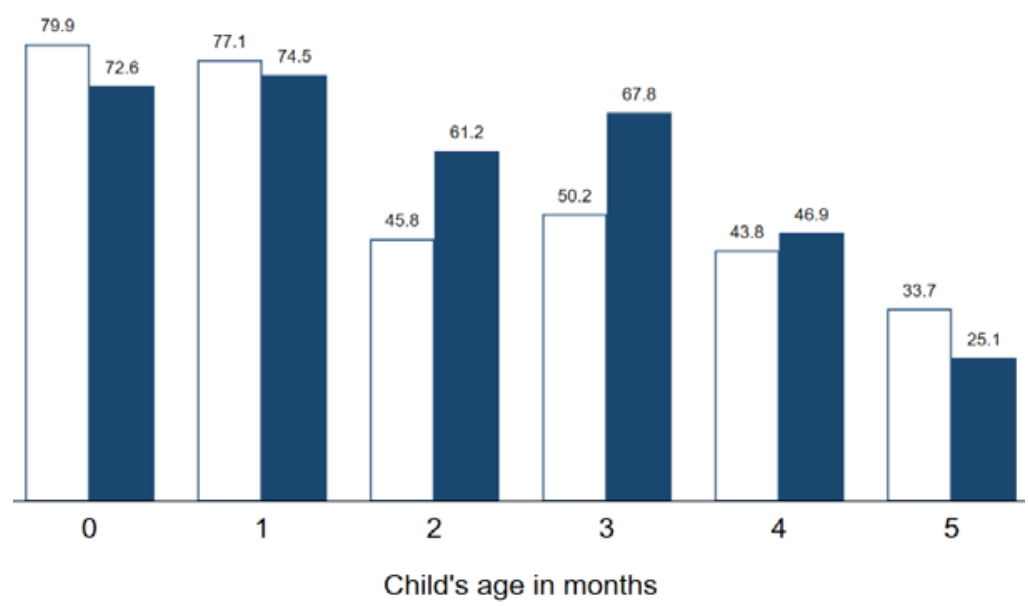

Source: Authors' analysis of Ethiopia Demographic and Health Surveys.

By international standards, both the prevalence and duration of exclusive breastfeeding are high in Ethiopia (Figure 16). Continued breastfeeding up to two years is also one of the highest in the world (UNICEF 2019). However, complementary diets are suboptimal, as illustrated by the 
coincidence of peaks in morbidity and growth faltering during the period over which complementary foods are introduced into the diet of a young child. Delayed introduction to complementary foods and low quantity and diversity in the foods given are some of the characteristics of complementary diets in Ethiopia. About 18 percent of children are not introduced to solid, semi-solid or soft foods in the recommended age period between six and eight months and only 7 percent meet the standard minimum adequate diet for young children (CSA \& ICF 2017).

Complementary diets remain primarily cereal-based with little consumption of animal source foods, fruit, and vegetables (Baye 2019; CSA \& ICF 2017; EPHI 2013; Headey et al. 2018). Minimum dietary diversity for young children is met when at least five of eight food groups (including breastmilk) are consumed by the child in the preceding 24 hours. In 2016, only 12.5 percent of children aged 6 to 23 months achieved this. Although this is an improvement relative to figures in 2011 (4.4 percent), progress was uneven (Figure 17).

Figure 17. Number of food groups reported consumed by children aged 6 to 23 months in 2011 and 2016 (left) and in rural and urban Ethiopia (right), by age of child,
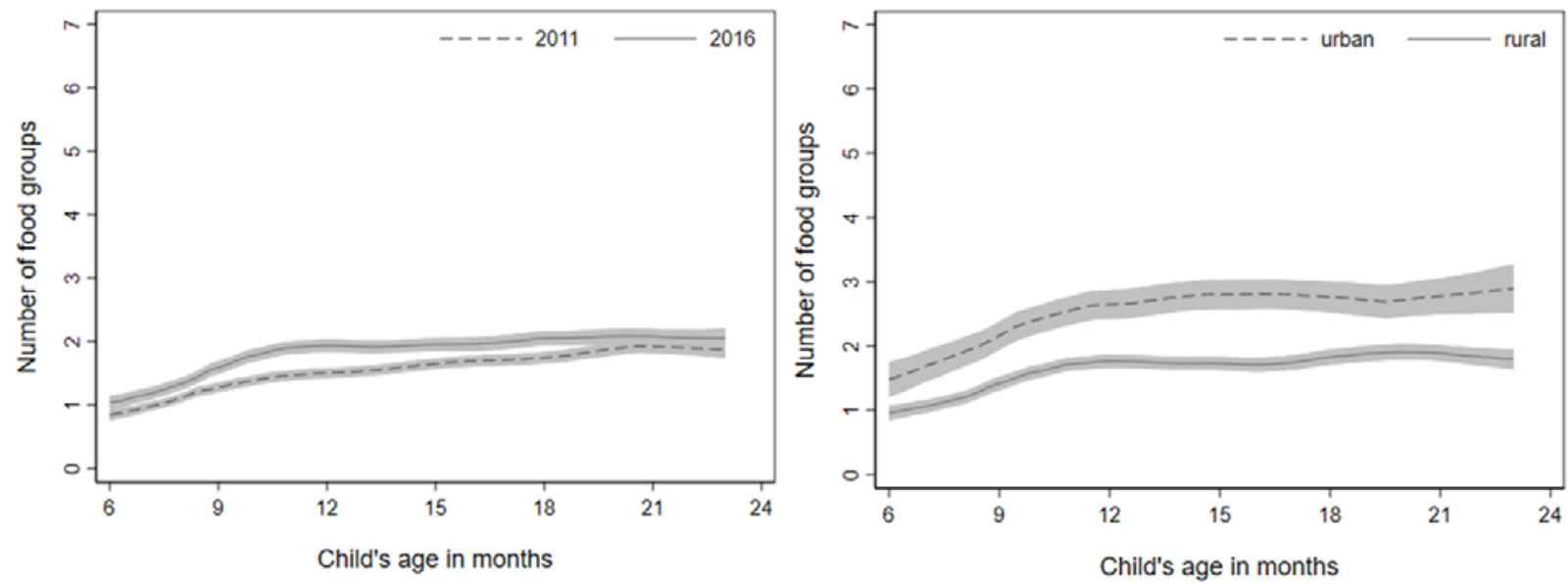

Source: Authors' analysis of Ethiopia Demographic and Health Surveys.

Note: Shaded areas are 95 percent confidence intervals around the plotted estimates.

Much of the progress seen was only among children in the wealthiest quintile of households (Figure 18). However, even in the richest quintile, less than 30 percent of the children met the minimum dietary diversity standard in 2016. This suggests that in addition to economic constraints, nutrition literacy and cultural issues, such as religious fasting, can be a factor. Recent studies among Orthodox Christians in different parts of Ethiopia have shown that the consumption of animal source foods is particularly low during fasting seasons (Abegaz et al. 2018). Although children, pregnant and lactating women are exempt from fasting, the fear of 'contaminating' utensils with animal source foods, while preparing meals for the family, often lead to the avoidance of animal source foods altogether (Bazzano et al. 2018). 
Figure 18. Children aged 6 to 23 months meeting the minimum dietary diversity standard, by wealth quintile, 2011 and 2016

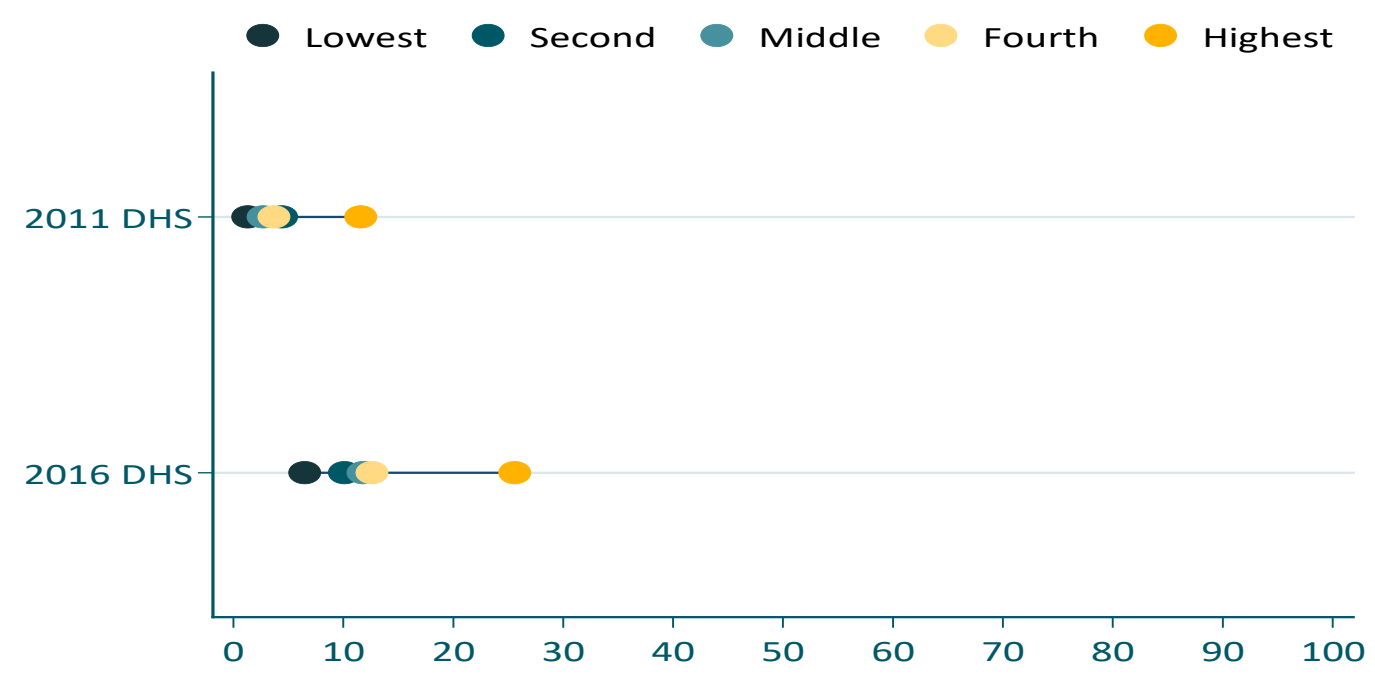

Source: Authors' analysis of Ethiopia Demographic and Health Surveys.

The few studies that estimated dietary diversity in women suggest that the proportion of women meeting the minimum of consuming five out of ten food groups is very low. The National Nutrition Program endline survey reported that 20 percent of women meet the minimum dietary diversity standard for women (EPHI 2015). In a survey conducted in four regions in 2017 and 2019, the average PSNP mother consumed two or three foods groups only (Berhane et al. 2020). In another study from Amhara region, less than 25 percent of women met the minimum dietary diversity standard for women (Baye, Choufani, et al. 2019). Similarly, in a smaller study in Oromia region, only 4 percent of adolescent girls met the standard (Seyoum et al. 2019). Although these are not representative of adolescents and women of reproductive age, they illustrate that diets are often devoid of nutrient-dense foods, such as animal source foods, fruit, and vegetables (Abegaz et al. 2018; Baye, Choufani, et al. 2019; Hirvonen et al. 2016). Low dietary diversity in adolescence and adulthood increases the risk of micronutrient deficiencies that are associated with various noncommunicable diseases (Forouzanfar et al. 2016).

About 20 percent of children in rural areas and 10 percent in urban areas are stunted at birth, which is suggests suboptimal maternal nutrition (Golan et al. 2019). Recent prospective cohort studies from Ethiopia have shown that maternal dietary diversity is low, partly due to food taboos and misperceptions (Zerfu et al. 2016). Pregnant women who had lower dietary diversity had a significantly increased risk of adverse pregnancy outcomes, including low birth weight (Zerfu et al. 2016; 2018). This along with delayed first antenatal care visits (Tesfaye et al. 2017) and low adherence to iron and folic acid supplementation (Gebremedhin et al. 2014) can increase the risk of fetal growth restriction. More attention should be paid to women's and adolescent girls' nutrition. 
Figure 19. Adults in Ethiopia meeting recommendation of World Health Organization of five servings daily of fruit or vegetables, by region, 2015

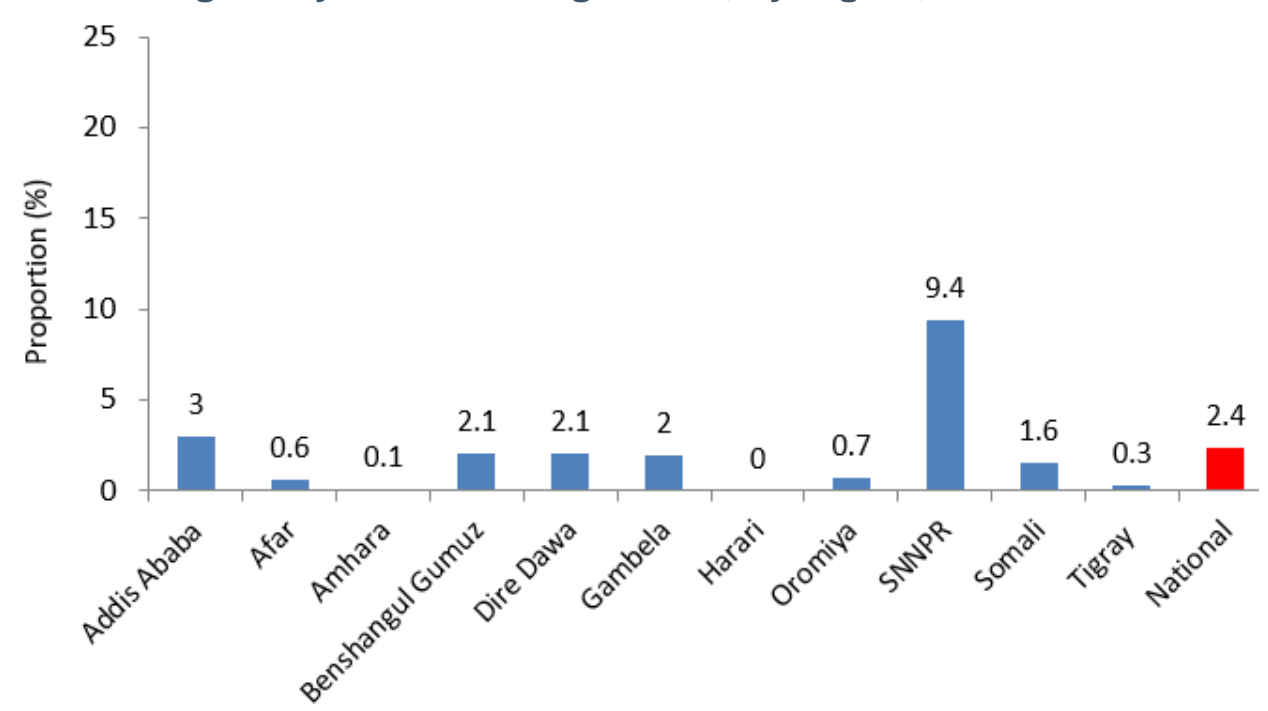

Source: Adapted from Gelibo et al., (2017)

Not only women and children, but the population in general has extremely low consumption of fruit and vegetables (Figure 19). Only 2.4 percent of the national population meets the recommendation of the World Health Organization (WHO) or five servings of fruit or vegetables per day. Also alarming is high salt intake across all regions of Ethiopia (Figure 20).

Figure 20. Average salt intake by the adult population of Ethiopia, by region, 2015

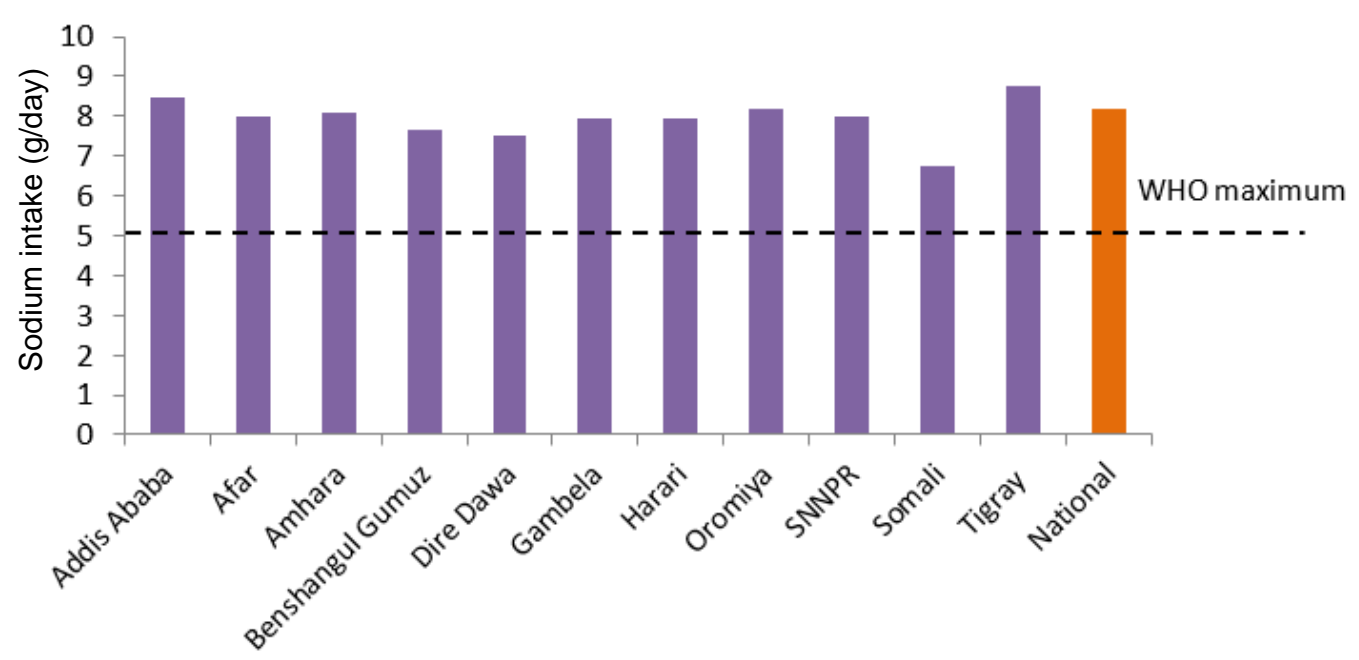

Source: Adapted from Challa et al., (2017); 24-hour urine excretion estimated using spot urine adjusted for creatinine.

Urban diets in Ethiopia are changing fast, but not necessarily becoming healthier (Wolle et al. 2020). Both the quantities of foods consumed and energy intakes have considerably increased (Worku et al. 2017). Processed foods are penetrating the market at a rapid pace (Melesse et al. 2019; Stuckler et al. 2012). With increasing incomes, out of home consumption and the need for convenience foods has grown (Minten, Dereje, et al. 2018). Such rapid food system transformations have led to a double burden of malnutrition and a spike in non-communicable diseases in other low and middle income countries (Popkin 2017). Unless food systems are shaped to support healthy diets, the disease burden related to malnutrition is likely to increase further.

Food safety is another parameter of diet quality that is often overlooked. Nutrient-dense foods, such as fruit, vegetables, dairy, and meat, have in many instances in Ethiopia been found to 
commonly contain high concentrations of microbial pathogens (Amenu et al. 2016; Kechero et al. 2019; Molla et al. 2004). A recent review of evidence from Ethiopia also suggested high food safety risks related to mycotoxins (Ayelign \& De Saeger 2020). The burden of food-borne diseases in Ethiopia is high, with recent estimates indicating large economic losses (Grace et al. 2018). Efforts to improve diet quality and promote health should give adequate attention to issues of food safety.

\subsection{Drivers of diet quality}

To understand the drivers of diet quality, it is important to place diets in a food systems framework (Figure 21). The consumer's knowledge, purchasing power, time, and preferences influence dietary choices and thus affect the quality of the diet they consume. In turn, consumer behaviors can be influenced by the food environment, such as promotion and labeling, accessibility of certain foods, price and nutrient quality. The food environment is itself determined by the food supply system, that is what and how foods are produced, stored, transported, retailed, and processed. Ethiopia has diverse agro-ecologies and livelihood systems that can influence the production, marketing, and consumption of foods. While this review provides an overview of the food system at national level, Hirvonen and Wolle provide detailed region-specific analyses on the consumption, production, market access, and affordability of nutritious foods (2019a; 2019b; 2019c; 2019d; 2019e; 2019f).

Figure 21. Conceptual framework linking food systems to diet quality

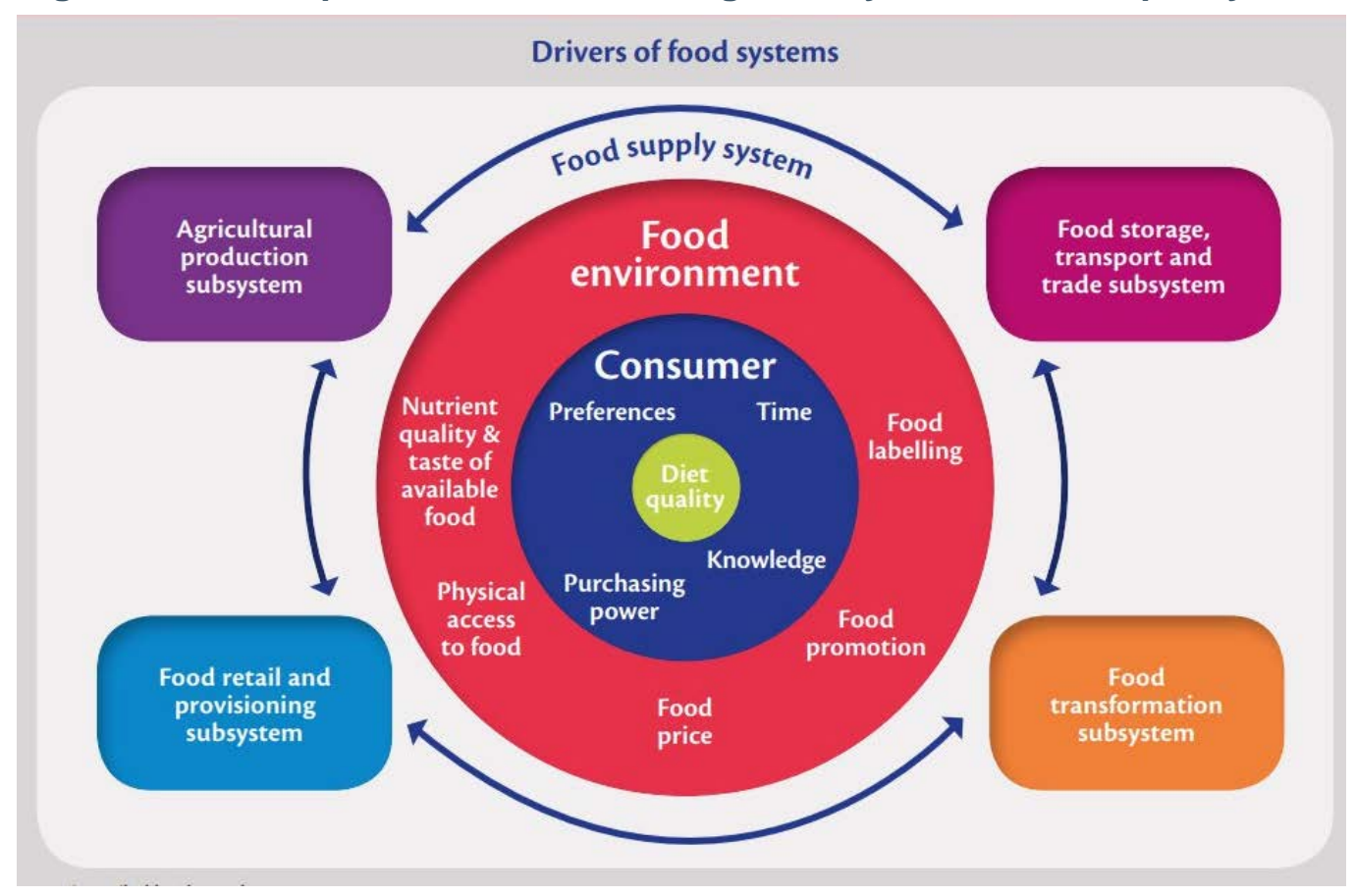

Source: GLOPAN (2016).

\section{Consumer behavior}

Improving knowledge of mothers through various forms of nutrition education has been the mainstay of nutrition interventions delivered by the health sector. Health Extension Workers (HEW) teach about breastfeeding, appropriate complementary feeding, and related WASH practices, and also perform growth monitoring of children. This has been instrumental in improving knowledge and practices related to infant and young child feeding (Abebe et al. 2016; Kim et al. 2016). Studies have also shown that using multiple platforms and techniques, such as interpersonal communication, community mobilization, and mass media, has positive impacts on child feeding and stunting (Kim et al. 2019). Involving male partners in infant and young child feeding and 
integrating nutrition-sensitive agriculture has also been associated with improved dietary diversity (Gebremedhin et al. 2017). In addition, religious leaders and community leaders can play a key role in shaping food choices, since food choices in Ethiopia are intrinsically linked to religion, e.g., Orthodox fasting, or other traditions. Realizing this, social-behavioral change communications (SBCC) in nutrition and health have increasingly involved religious leaders and community leaders (Asfaw et al. 2019). Although systematic evaluations of the impact of involving religious and community leaders are few, qualitative evidence of the benefits of such approaches has been documented, including from other sectors than nutrition, e.g., HIV (WHO 2016).

However, the reach of such SBCC interventions is limited (Abate et al. 2019; Abebe et al. 2016). Two survey rounds (2017 and 2019) conducted in woredas in which the Productive Safety Net Programme (PSNP) in being implemented in Amhara, Tigray, Oromia and SNNP regions revealed that, despite some regional disparities, caregivers' contact rate with HEWs was generally very low (Figure 22). Overall, 33 percent of caregivers of children aged 6 to 23 months reported having had contact with HEWs in the three months preceding the surveys (Berhane et al. 2020). These are very low contact rates given the very young age of the children and the several interventions being delivered through the health system during this period.

Figure 22. Exposure of Productive Safety Net Programme households to nutrition messages from Health Extension Workers, March 2019 and August 2019, by region

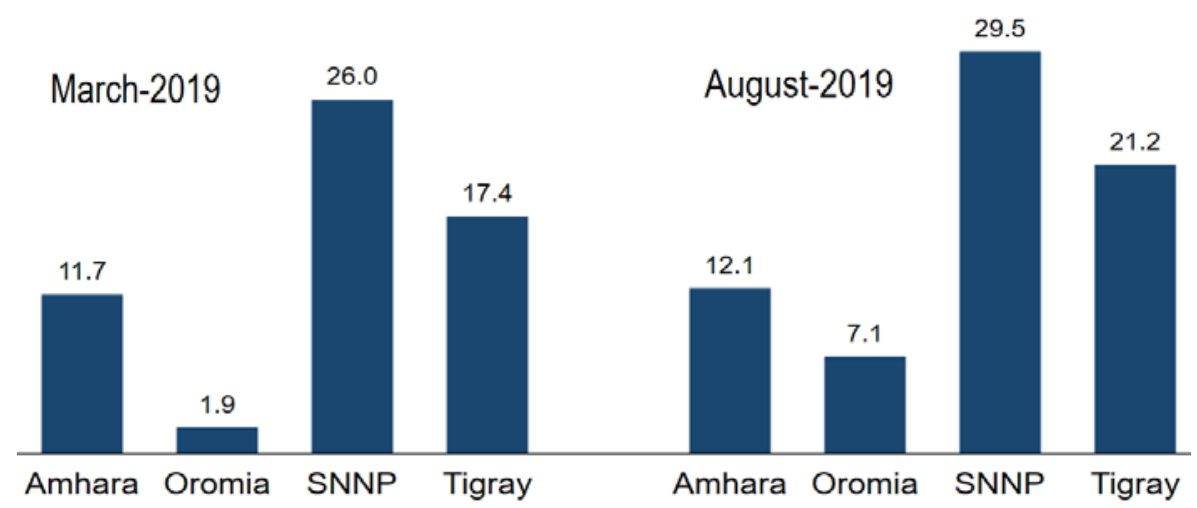

Source: Analyses of 2019 PSNP survey.

Note: Also includes exposure to local staff of Health Development Army.

The findings of the PSNP study are supported by nationally representative data on coverage of essential health care. The Composite Coverage Index $(\mathrm{CCl})$ is a weighted score reflecting coverage of eight reproductive, maternal, neonatal, and child health interventions along the continuum of care (Boerma et al. 2008; Wehrmeister et al. 2016). These are:

- Demand for family planning satisfied (modern methods);

- Antenatal care coverage (at least four visits);

- Births attended by skilled health personnel;

- BCG immunization coverage among one-year-olds;

- Measles immunization coverage among one-year-olds;

- DTP3 immunization coverage among one year-olds;

- Children aged less than five years with diarrhea receiving oral rehydration therapy and continued feeding; and

- Children aged less than five years with pneumonia symptoms taken to a health facility.

The $\mathrm{CCl}$ for Ethiopia confirmed the observed disparities by rural/urban and wealth quintile (Figure 23). In 2016, the CCI for wealthiest quintile of household (65 percent) was twice the value of the $\mathrm{CCl}$ for the poorest quintile (32 percent). Similarly, the $\mathrm{CCl}$ for urban households was 1.7 times higher than for rural households (71 percent for urban and 42 percent for rural households). Given that the health system is used to deliver SBCC messages, such disparities due to 
remoteness need to be addressed to accelerate improvements in health and nutrition status across Ethiopia(Abate et al. 2019).

Figure 23. Composite coverage index in Ethiopia of essential reproductive, maternal, newborn, and child health interventions, by household wealth quintile

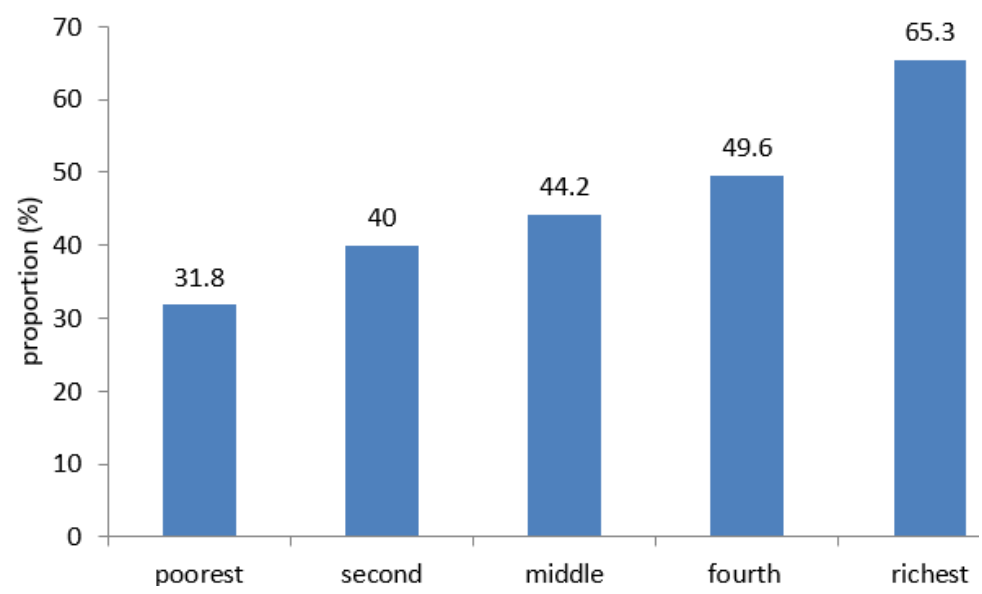

Source: Authors' calculation using DHS

Besides health care access and reach, the quality of the counseling delivered by the HEWs determines the effectiveness of SBCC (Abebe et al. 2016; Kim et al. 2019). The quality of the counseling is, in turn, dependent on a number of factors, including the motivation, skills, and workload of the HEWs and the amount of contact time they have with clients. A breakdown of the daily activities of HEWs by Mangham-Jefferies et al. (2014) illustrates the numerous activities on average that each HEW performs in a day. This study found that only 5.5 percent of the HEW time is allocated to nutrition interventions (Figure 24).

Figure 24. Health extension workers time allocation by health package

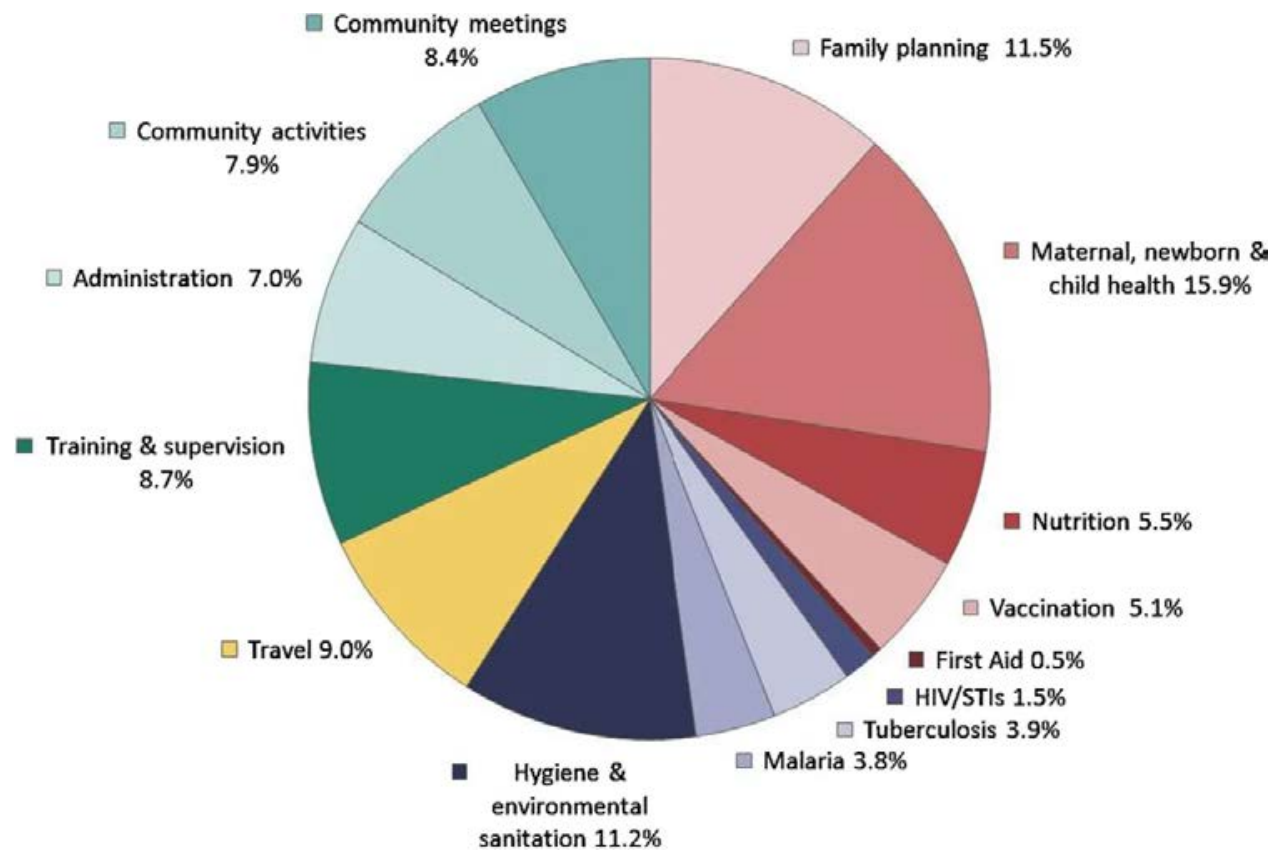

Source: Mangham-Jefferies et al. (2014).

The busy workload of the HEW can lead to high levels of burnout, which can in turn adversely affect the effectiveness of the SBCC messages they provide, as well as their mental health. A recent survey administered a psychometric test to HEWs in PSNP woredas. High levels of emotional exhaustion (11 percent), depersonalization (11 percent) and low personal accomplishments (49 percent) were found (Berhane et al. 2020). While most HEWs reported that 
they were highly motivated, many felt that they were not effectively coping with the rising demands of their job. They also felt they needed more training and better incentives and the health posts in which they worked needed to be supplied with basic services, such as electricity and water. Addressing these bottlenecks and supporting nutrition education with food-based dietary guidelines is essential to ensure that diets become central in nutrition messaging.

\section{Food environment}

Studies in rural areas of Ethiopia have shown that nutrition education was more effective in improving a child's diet when households had access to markets (Hirvonen et al. 2017). Market access has also been shown to mitigate the negative effect on child diets of seasonality in crop production (Abay \& Hirvonen 2017).

However, access to market is futile if nutrient-dense foods are not affordable. Unfortunately, prices of nutrient-dense foods, such as animal source foods, fruit, and vegetables, have been on the rise, whereas the prices of sugar and oil have been declining (Bachewe et al. 2017). On average, 11 percent of the income of the average Ethiopian household is needed to meet the WHO recommended intake of fruit and vegetables (Hirvonen et al. 2018). This figure is even higher for households in the poorest wealth quintile (27 percent). This price barrier makes the adoption of the fruit and vegetable consumption recommendations prohibitive. The same is true for other nutrientdense foods (Headey \& Alderman 2019; Hirvonen et al. 2020). The high prices are due to limited production, high transaction cost, e.g. transport, and the perishability of nutrient-dense foods that is exacerbated by the limited storage capacity, e.g. no cold chains. More research is needed to understand the production and marketing barriers to increased consumption of nutrient-dense foods.

\section{The food supply}

The national food supply has been expanding over the past decade. In 2015, the energy contribution of national food production reached 3,500 kcal/capita/day (Baye, Hirvonen, et al. 2019). However, this increase has come mainly from the cereal sector (Figure 25).

Figure 25. Agricultural production in Ethiopia, by major food groups, 2011 to 2015

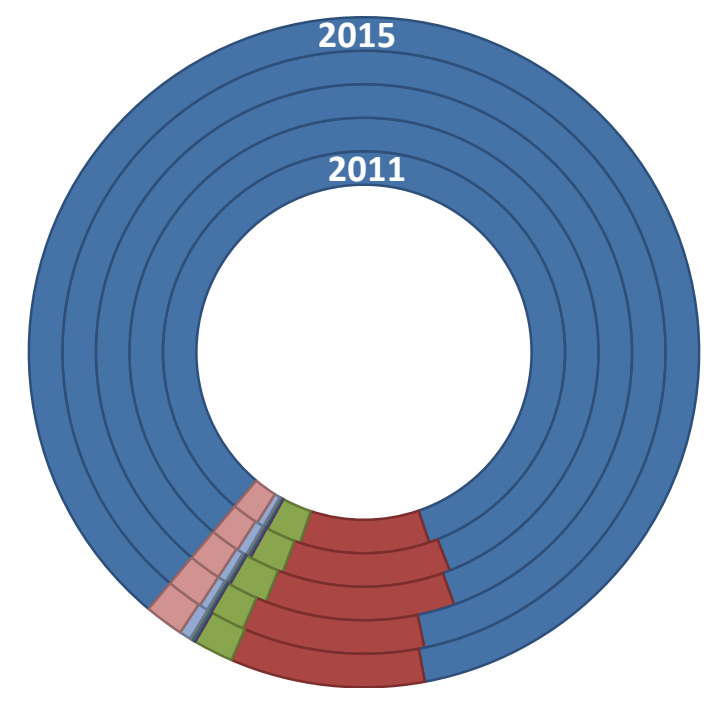

$\square$ Grains, roots and tubers

$\square$ Legumes and nuts

$\square$ Dairy products

$\square$ Poultry, fish, meat

$\square$ Eggs

$\square$ Vitamin A rich fruits and vegetables

$\square$ Other fruits and vegetables

$\square$ Other foods

Source: Baye, Hirvonen, et al. 2019

Figure 26, using a Shannon index of diversity, shows how the diversity of food production, calculated based on the same seven food groups used to calculate the Minimum Dietary Diversity Score has decreased between 2011 and 2015. This has led to an increasing deficit in the supply of nutrient-dense foods, which partly explains the rising prices of these commodities. Boosting 
production of nutrient-dense foods, such as dairy, fruit, and vegetables, is needed (Benfica \& Thurlow 2017; Minten, Habte, et al. 2018).

Figure 26. Agricultural production diversity, 2011-15

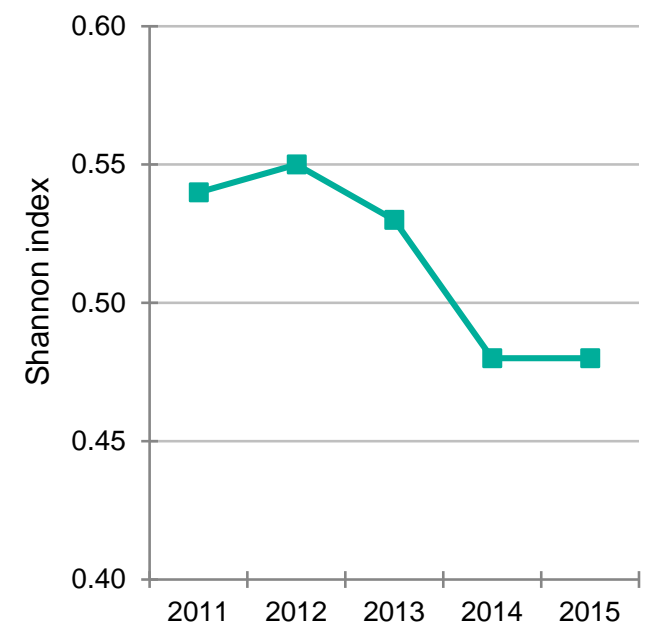

Source: Baye, Hirvonen, et al. (2019)

Using an economy-wide model, Benfica \& Thurlow (2017) found that expansion of fruit and vegetable value chains can lead to a win-win situations that generate economic growth, reduce national and rural poverty, create jobs, and diversify diets. Therefore, promotion of fruit and vegetable production should be prioritized.

However, access to water is an important precondition for fruit and vegetable production (Hirvonen \& Headey 2018). Figure 27 shows that many places in the country have irrigation potential. Evidence from a recent study comparing the nutritional status of households that practice irrigated farming to non-irrigators suggest that irrigators had significantly higher dietary diversity and were less affected by seasonal fluctuations (Baye, Choufani, et al. 2019; Passarelli et al. 2018).

Figure 27. Map showing rainfall pattern across Ethiopia and sites with irrigation potential

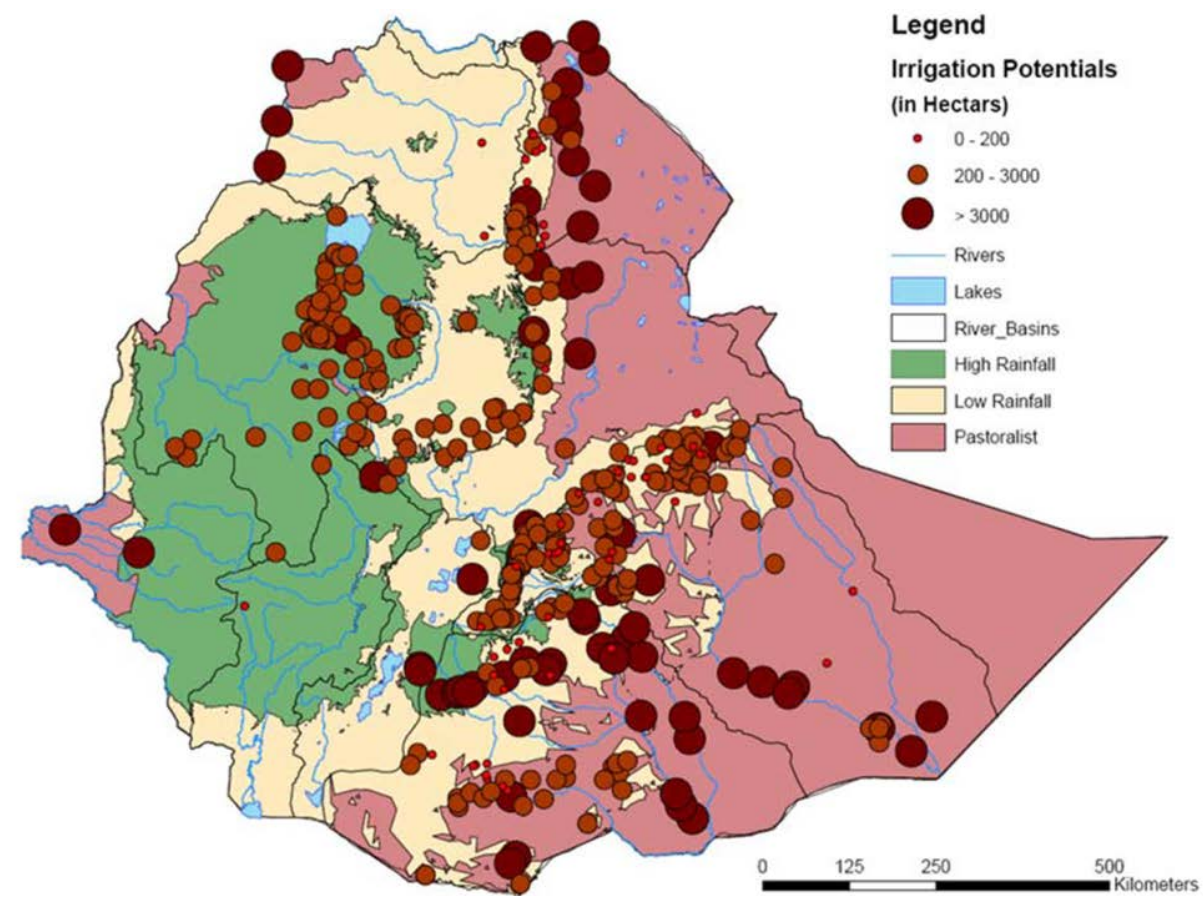


Recent national food and nutrition policy strategies (FDRE 2018; GFDRE 2016) highlight the need to reduce post-harvest losses as key to improving food and nutrition security in the country. However, reliable evidence of the magnitude of the post-harvest losses in Ethiopia is limited. The available evidence from the cereal sector shows that post-harvest losses are surprisingly small of between 2 and 4 percent (Bachewe et al. 2018; Minten et al. 2020). In the dairy sector, Minten et al., (2020) estimate that losses equal 2 percent for raw, unprocessed, milk and 4.3 percent for pasteurized milk. With the caveat that reliable and representative estimates of post-harvest losses from the fruit and vegetable sectors are not yet available, increasing yields that still lag far behind international or regional production levels is likely to offer a more promising policy option to increasing food supply and improving food and nutrition security than the focus on reducing or eliminating food loss and waste (FAO 2019).

\section{PROGRAMS, POLICIES, AND CHALLENGES AHEAD}

Several policy instruments to guide efforts to improve nutrition and health have been put in place in Ethiopia. These include the National Nutrition Strategy, the National Nutrition Programme, and the Seqota Declaration (Figure 26).

Figure 28. Selected policies and programs of the government of Ethiopia related to nutrition

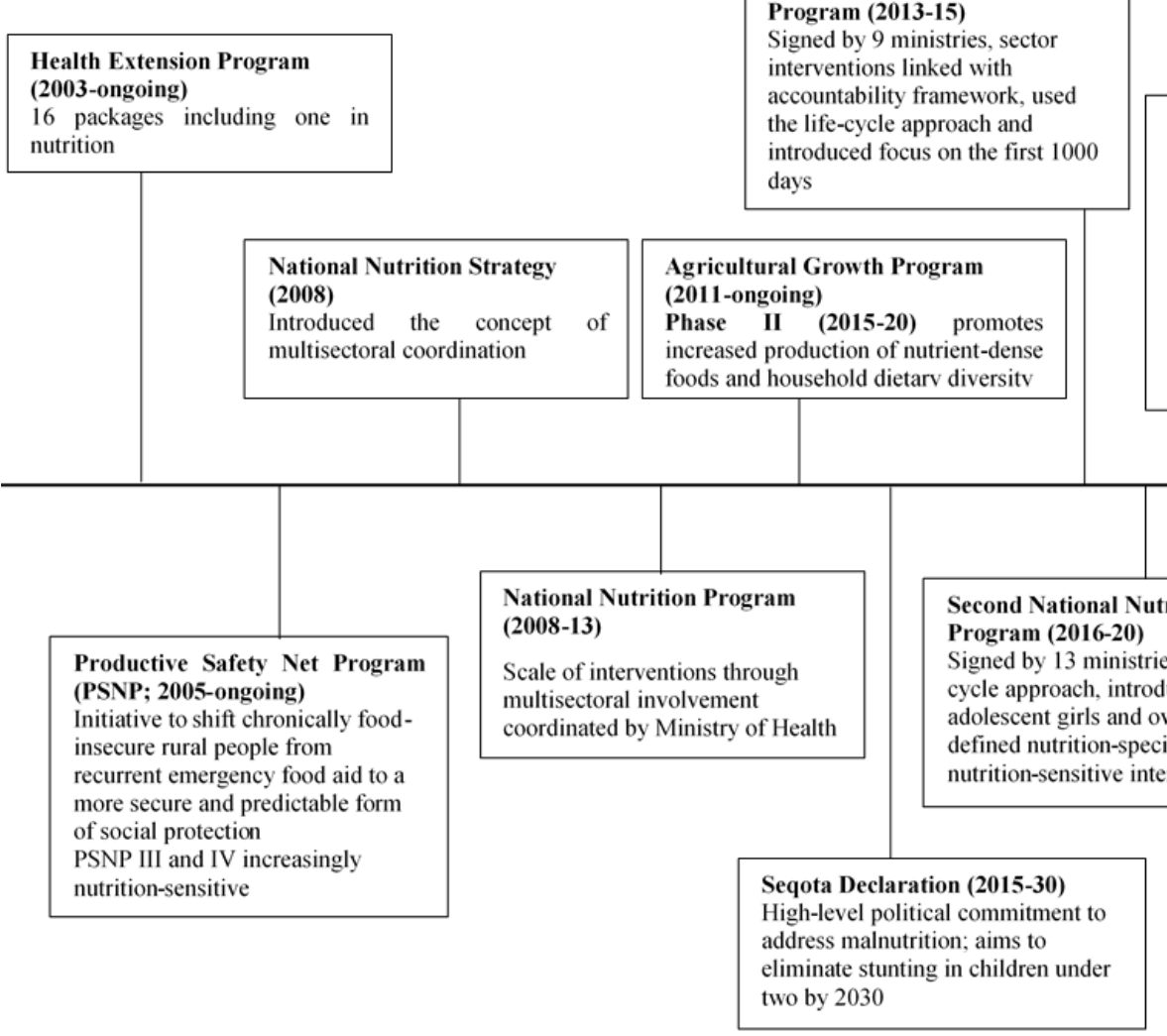

Sustainable undernutrition reduction program (SURE; 2017 ongoing)

Government-led multisectoral health and agriculture sector programme Enhances community-based nutrition using health and agriculture extension programmes to improve

complementary feeding and dietary diversity

Most of these policies have evolved over time to become more ambitious, to embrace multisector coordination and approaches, and to be more comprehensive with increased focus on a life-cycle approach. For example, the recent Food and Nutrition Policy considers all forms of malnutrition. The Policy has seven pillars (Text Box 1 ) that require better synergies and alignment of food and health systems (Bossuyt 2019). 
1. Ensure availability, accessibility and utilization of diversified, safe, and nutritious foods in a sustainable way.

2. Ensure the safety and quality of foods from farm to table.

3. Improve postharvest management of agricultural food products.

4. Ensure optimum nutrition at all stages of life.

5. Provision of timely and appropriate food and nutrition emergency response for natural and manmade disasters.

6. Strengthen food and nutrition communication.

7. Establish and strengthen food and nutrition governance.

Source: FDRE 2018

The Ethiopian policy landscape thus provides an enabling environment to eliminate all forms of malnutrition. What is needed now is better alignment among different policy instruments and effective and timely action that is supported by evidence (Ayele et al. 2020). Except in a few cases, like the PSNP, little empirical evidence exists on the nutritional impact of each of these policy initiatives or combinations of initiatives. This is a missed opportunity to learn what has and has not worked and to adapt those initiatives that have been effective to make policies and programs more effective. A substantial savings in resources and much greater impact could be expected with investments in operational research. Such studies could monitor and evaluate the impact of programs in order to better inform their timely adaptation, scale-up, or phase-out. As Ethiopia aspires to eradicate all forms of malnutrition, several policy and programmatic reforms that may be considered are outlined in Box 2.

Text Box 2. Possible policy and programmatic reforms for improving diets and nutrition in Ethiopia

Increase production and consumption of nutrient-dense foods using nutrition-sensitive fiscal policies. Revoke sugar subsidies, address constraints to expanding production of nutrient-rich foods, and remove value-added tax from nutrient-dense foods, such as fruit and vegetables. All of these actions could be viable policy or programmatic options for urgent implementation. Fiscal policies have the potential to shape the domestic food environment (Abay et al. 2020).

Address risk of food safety. The increasing reliance on markets for food provisioning and efforts to increase consumption of nutrient-dense foods that frequently are perishable is likely to increase food safety concerns. Strengthening monitoring along the value chain, increasing the capacity of value chain actors, and improving WASH conditions will be critical.

Maintain the relatively high rates of breastfeeding. More stringent laws and regulations on the marketing of breastmilk substitutes are needed to sustain the benefits of prolonged breastfeeding.

Bridge inequalities through social protection and school feeding. Wealth inequalities and rural/urban disparities should be addressed to prevent further widening of dietary and nutritional inequalities. Given the long-term consequences of poor diets and malnutrition, such inequalities should be addressed through nutrition-sensitive social protection, e.g., PSNP, and school feeding programs. 
Increase the scope of social and behavior change communication (SBCC) topics and targets while ensuring adequate support to Health Extension Workers. Expanding nutrition education targets to reach not only women and children, but also men, adolescents and urban households is needed given the widespread consumption of unhealthy diets and the high prevalence of malnutrition and associated diet-related diseases. However, such measures would require an increase in the number of HEWs and strengthening their capacity.

Greater investments in implementation research. Implementation research and program evaluation is needed to understand what has and has not worked, but also what can be done to improve the effectiveness of diet and nutrition-focused programs and policies.

Strengthen implementation capacity. The complexity of the problem of malnutrition requires multi-sectoral interventions. Given the tradition of sector-specific policymaking and implementation, the capacity of national and local government agencies should be built so that they can better design, lead, coordinate, and effectively implement complex interventions (Ayele et al. 2020). Moreover, government's capacity to respond in a timely and effective manner to increasing shocks, whether economic, weather, conflict, or health, should continue to be strengthened. The pace at which this capacity is developed will determine how quickly impact can be seen on the ground.

Source: Authors' compilation.

Diet and nutrition-focused policies and programs in Ethiopia also need to consider the following future challenges:

- Demographic changes - Ethiopia's population is expected to continue to grow both in urban and rural areas. The population growth in the urban areas is faster, but given the size of the rural population, it will take decades before the urban population eclipses the rural population (Minten et al. 2018). Rapid population growth will stretch the nation's ability to provide decent education, health care, and other basic services. This also increases the demand for food, putting more pressure on land, water, and natural resources (Springmann et al. 2018).

- Nutrition transition - With urbanization and income growth, dietary patterns will shift towards higher consumption of animal products and processed foods (Worku et al. 2017; Minten et al. 2018). This, combined with sedentary lifestyles, is likely to increase the risk of overweight and obesity (Popkin et al. 2012), as already witnessed in urban areas.

Overweight and obesity, undernutrition, and micronutrient deficiencies will thus constitute a triple-burden that challenges our ability to eradicate all forms of malnutrition (Mwangome \& Prentice 2019).

- Pervasive inequalities - Income, rural/urban, and gender inequalities are impeding poverty reduction, economic growth, and the eradication of all forms of malnutrition (Baye et al. 2020; Perez-Escamilla et al. 2018). Women's social and economic status is a key determinant of maternal and child nutrition, thus the returns to investing in efforts to empower women would be very high (Madzorera \& Fawzi 2020; Yaya et al. 2020).

- Climate change and degradation of natural resources - Climate change, extreme weather events, and the frequency and intensity of droughts are increasing (Dai 2013; Hoegh-Guldberg et al. 2018). These impacts will vary across Ethiopia's agro-ecological zones (Admassu et al. 2012), but increasing weather anomalies, whether droughts or floods, are likely to cause localized food shortages, especially in more remote areas that are poorly connected to the major value chains and food markets (Hirvonen et al. 2020). 


\section{EVIDENCE GAPS}

We identify several pressing evidence gaps that need to be filled so that diet and nutrition-focused policies and programs in Ethiopia can be better designed and implemented.

- Most Ethiopians continue to rely on rain-fed agriculture, making food output, diets, and health outcomes prone to sizable seasonal fluctuations. Consequently, nationally representative, longitudinal data that allow a better understanding of seasonality in diets, nutrition, and health are needed.

- The etiology of anemia needs to be better understood to maximize benefits and reduce adverse effects of micronutrient interventions.

- More reliable evidence on the magnitude of post-harvest losses along the value chain needs to be generated. Once these magnitudes are known, the cost and benefits of reducing post-harvest losses need to be carefully weighed against alternative interventions aiming to improve food and nutrition security in the country.

- Studies evaluating how the establishment of agro-processing industries, such as in industrial parks, shape the food supply, food environment, consumer behavior, diets, and health are needed.

- Large-scale diet and nutrition-focused programs need to be evaluated and their individual as well as combined effects be estimated to the extent possible. It is only with timely and rigorous evaluations that effective interventions can be designed and adapted for maximal impact.

\section{SUMMARY AND WAY FORWARD}

Ethiopia has witnessed significant reductions in child mortality, undernutrition, and communicable diseases over the past two decades, but more substantial and faster progress is still needed. The rise in overweight, obesity, and non-communicable diseases, particularly in urban areas, is alarming and requires urgent policy and programmatic attention. Unhealthy diets are key drivers of both forms of malnutrition and are the underlying cause of significant proportion of communicable and non-communicable diseases. Maintaining the relatively high breastfeeding practices and increasing the diversity of diets will be critical. Implementation is warranted of effective social and behavior change communication that shapes consumer behavior to adopt healthy dietary patterns, while bridging gaps in reach and in the quality of nutrition messaging. The Health Extension Programme, which is the cornerstone of the health sector transformation may need to be redesigned in a way that improves reach, quality, and minimize the risk of burnout for Health Extension Workers. Interventions focusing on making healthy diets affordable, accessible, and available are urgently needed. 


\section{REFERENCES}

Abate, G.T., M. Dereje, K. Hirvonen, \& B. Minten. 2019. Geography of Public Service Delivery in Rural Ethiopia. ESSP Working Paper 133. Washington, DC and Addis Ababa, Ethiopia: International Food Policy Research Institute (IFPRI) and Federal Democratic Republic of Ethiopia Policy Studies Institute.

Abay, K., H. Ibrahim, \& C. Breisinger. 2020. Food Policies and Obesity in Low and Middle Income Countries. Vol. 28. MENA RP Working Paper 28. Washington, DC: International Food Policy Research Institute (IFPRI).

Abay, K. \& K. Hirvonen. 2017. "Does Market Access Mitigate the Impact of Seasonality on Child Growth? Panel Data Evidence from Northern Ethiopia." The Journal of Development Studies 53 (9): 1414-29.

Abebe, Z., GD. Haki, \& K. Baye. 2016. "Health Extension Workers' Knowledge and Knowledge-Sharing Effectiveness of Optimal Infant and Young Child Feeding Are Associated with Mothers' Knowledge and Child Stunting in Rural Ethiopia."Food and Nutrition Bulletin 37 (3): 353-63.

Abegaz, GA., I.W. Hassen, \& B. Minten. 2018. Consumption of Animal-Source Foods in Ethiopia: Patterns, Changes, and Determinants. ESSP Working Paper 113. Washington, D.C. and Addis Ababa, Ethiopia: International Food Policy Research Institute (IFPRI) and Ethiopian Development Research Institute (EDRI).

Admassu, H., M. Getinet, \& T.S. Thomas. 2012. "East African Agriculture and Climate Change: A Comprehensive Analysis-Ethiopia." IFPRI Issue Brief 76 Washington, D.C.: International Food Policy Research Institute (IFPRI).

Amenu, K., D. Shitu, \& M. Abera. 2016. "Microbial Contamination of Water Intended for Milk Container Washing in Smallholder Dairy Farming and Milk Retailing Houses in Southern Ethiopia." SpringerPlus 5 (1): 1195.

Asfaw, S., S. Morankar, M. Abera, A. Mamo, L. Abebe, N. Bergen, M.A. Kulkarni, \& R. Labonté. 2019. "Talking Health: Trusted Health Messengers and Effective Ways of Delivering Health Messages for Rural Mothers in Southwest Ethiopia." Archives of Public Health 77 (1): 8.

Ayele, S., E.A. Zegeye, \& N. Nisbett. 2020. "Multi-Sectoral Nutrition Policy and Programme Design, Coordination and Implementation in Ethiopia." Brighton: IDS.

Ayelign, A., \& S. De Saeger. 2020. "Mycotoxins in Ethiopia: Current Status, Implications to Food Safety and Mitigation Strategies." Food Control 113, 107163. https://doi.org/10.1016/j.foodcont.2020.107163.

Bachewe, F., B. Minten, A.S. Taffesse, K. Pauw, A. Cameron, \& T.G. Endaylalu. 2018. "Farmers' Grain Storage and Losses in Ethiopia: Measures and Associates." Journal of Agricultural \& Food Industrial Organization 18 (1) 0190059. doi: https://doi.org/10.1515/jafio-2019-0059

Bachewe, F., B. Minten, \& F. Yimer. 2017. The Rising Costs of Animal-Source Foods in Ethiopia: Evidence and Implications. ESSP Research Note 67, Addis Ababa: International Food Policy Research Institute.

Baye, K. 2019a. "Maximising Benefits and Minimising Adverse Effects of Micronutrient Interventions in Low- and MiddleIncome Countries." Proceedings of the Nutrition Society, 1-7. https://doi.org/10.1017/S0029665119000557.

Baye, K. 2019b. "Prioritizing the Scale-Up of Evidence-Based Nutrition and Health Interventions to Accelerate Stunting Reduction in Ethiopia." Nutrients 11 (12): 3065.

Baye, K., J. Choufani, D. Mekonnen, E. Bryan, C. Ringler, J.K. Griffiths, \& E. Davies. 2019. Irrigation and Women's Diet in Ethiopia A Longitudinal Study. IFPRI Discussion Paper 1864. Washington, DC: International Food Policy Research Institute (IFPRI).

Baye, K, K. Hirvonen, M. Dereje, \& R. Remans. 2019. "Energy and Nutrient Production in Ethiopia, 2011-2015: Implications to Supporting Healthy Diets and Food Systems." PLOS ONE 14 (3): e0213182. https://doi.org/10.1371/journal.pone.0213182.

Baye, K., A. Laillou, \& S. Chitweke. 2020. "Socio-Economic Inequalities in Child Stunting Reduction in Sub-Saharan Africa." Nutrients 12 (1): 253.

Baye, K., C. Mouquet-Rivier, C.I. Vernière, C. Picq, \& J.P. Guyot. 2014. "Changes in Mineral Absorption Inhibitors Consequent to Fermentation of E Thiopian Injera: Implications for Predicted Iron Bioavailability and Bioaccessibility." International Journal of Food Science \& Technology 49 (1): 174-80.

Bazzano, A.N., K.S. Potts, \& A. Mulugeta. 2018. "How Do Pregnant and Lactating Women, and Young Children, Experience Religious Food Restriction at the Community Level? A Qualitative Study of Fasting Traditions and Feeding Behaviors in Four Regions of Ethiopia." PloS One 13 (12).

Benfica, R., \& J. Thurlow. 2017. Identifying Priority Value-Chains in Ethiopia. ESSP Working Paper 110. Washington, D.C. and Addis Ababa, Ethiopia: International Food Policy Research Institute (IFPRI) and Ethiopian Development Research Institute (EDRI).

Berhane, G., J. Golan, K. Hirvonen, J. Hoddinott, S. Kim, A.S. Taffesse, Y. Abate, et al. 2020. Evaluation of the Nutrition Sensitive Features of the Productive Safety Net Programme IV: Process and Impact. ESSP Working Paper 140. Washington, DC: International Food Policy Research Institute (IFPRI).

Berhane, Y., C.R. Canavan, A.M. Darling, C.R. Sudfeld, S.Vuai, R.Adanu, T.Bärnighausen, Y. Dessie, J.N. Bukenya, \& D. Guwatudde. 2019. "The Age of Opportunity: Prevalence of Key Risk Factors among Adolescents 10-19 Years of Age in Nine Communities in Sub-Saharan Africa." Tropical Medicine \& International Health 25(1), 15-32 
Bilal, N.K., C. H. Herbst, F.Zhao, A. Soucat, \& C.Lemiere. 2011. "Health Extension Workers in Ethiopia: Improved Access and Coverage for the Rural Poor." Yes Africa Can: Success Stiroes from a Dynamic Continent, 433-43.

Boerma, J.T., J. Bryce, Y. Kinfu, H. Axelson, \& C.G. Victora. 2008. "Mind the Gap: Equity and Trends in Coverage of Maternal, Newborn, and Child Health Services in 54 Countdown Countries." Lancet 371 (9620): 1259-67.

Bossuyt, A. 2019. "Moving toward Nutrition-Sensitive Agriculture Strategies and Programming in Ethiopia." Agriculture for Improved Nutrition: Seizing the Momentum. Chapter 16. Fan, Shenggen; Yosef, Sivan; Pandya-Lorch, Rajul (Eds.). Wallingford, UK: International Food Policy Research Institute (IFPRI) and CABI.

Canavan, C.R., \& W.W. Fawzi. 2019. "Addressing Knowledge Gaps in Adolescent Nutrition: Toward Advancing Public Health and Sustainable Development." Current Developments in Nutrition 3 (7): nzz062.

CSA\& ICF. (Central Statistics Agency \& 2017. Ethiopia Demographic and Health Survey 2016. Addis Ababa. http://dhsprogram.com/pubs/pdf/FR328/FR328.pdf.

Challa, F, Y.Tadesse, K. Mudie, G.Taye, T. Gelibo, A. Bekele, M. Sileshi, T. Getahun, Z. Geto, \& A. Ayalkebet. 2017. "Urinary Sodium Excretion and Determinates among Adults in Ethiopia: Findings from National STEPS Survey." Ethiopian Journal of Health Development 31 (1): 370-77.

Chaparro, C.M., \& P.S. Suchdev. 2019. "Anemia Epidemiology, Pathophysiology, and Etiology in Low-and MiddleIncome Countries." Annals of the New York Academy of Sciences 1450 (1): 15.

Dai, A. 2013. "Increasing Drought under Global Warming in Observations and Models." Nature Climate Change 3 (1): $52-58$.

EPHI(Ethiopian Public Health Institute). 2013. Ethiopian National Food Consumption Survey. Addis Ababa.

EPHI (Ethiopian Public Health Institute). 2015. Ethiopian National Nutrition Program Endline Survey. Addis Ababa.

EPHI (Ethiopian Public Health Institute). 2016. Ethiopian National Micronutrient Survey Report. Addis Ababa.

FAO. 2019. The State of Food and Agriculture 2019. Moving Forward on Food Loss and Waste Reduction. Rome.

FDRE. (Federal Democratic Republic of Ethiopia) 2018. Food and Nutrition Policy." Addis Ababa.

Forouzanfar, M.H., A. Afshin, L.T. Alexander, H.R. Anderson, Z.A. Bhutta, S.Biryukov, M. Brauer, R.Burnett, K.Cercy, \& F.J. Charlson. 2016. "Global, Regional, and National Comparative Risk Assessment of 79 Behavioural, Environmental and Occupational, and Metabolic Risks or Clusters of Risks, 1990-2015: A Systematic Analysis for the Global Burden of Disease Study 2015." The Lancet 388 (10053): 1659-1724.

Gashu, D., B.J. Stoecker, A. Adish, G.D. Haki, K. Bougma, \& G.S. Marquis. 2016. "Ethiopian Pre-School Children Consuming a Predominantly Unrefined Plant-Based Diet Have Low Prevalence of Iron-Deficiency Anaemia." Public Health Nutrition 19 (10): 1834-41.

Gebremedhin, S., K. Baye, T. Bekele, M. Tharaney, Y. Asrat, Y. Abebe, \& N. Reta. 2017. "Predictors of Dietary Diversity in Children Ages 6 to 23 Mo in Largely Food-Insecure Area of South Wollo, Ethiopia." Nutrition 33: 163-68.

Gebremedhin, S., A. Samuel, G. Mamo, T. Moges., \& T. Assefa. (2014). "Coverage, compliance and factors associated with utilization of iron supplementation during pregnancy in eight rural districts of Ethiopia: A cross-sectional study." BMC Public Health 14(1), 607.

Gebreyes, Y.F., D.Y. Goshu, T.K. Geletew, T.G. Argefa, T.G. Zemedu, K.A. Lemu, F.C.Waka, A.B. Mengesha, F.S. Degefu, \& A.D. Deghebo. 2018. "Prevalence of High Bloodpressure, Hyperglycemia, Dyslipidemia, Metabolic Syndrome and Their Determinants in Ethiopia: Evidences from the National NCDS STEPS Survey, 2015." PloS One $13(5)$.

Gelibo, T., K. Amenu, T. Taddele, G.Taye, M. Getnet, T. Getachew, A. Defar, H. Teklie, A. Bekele, \& F. Shiferaw. 2017. "Low Fruit and Vegetable Intake and Its Associated Factors in Ethiopia: A Community Based Cross Sectional NCD Steps Survey." Ethiopian Journal of Health Development 31 (1): 355-61.

GFDRE (Government of the Federal Republic of Ethiopia). 2016. National Nutrition Programme 2016-2020. Addis Ababa.

GLOPAN (Global Panel on Agriculture and Food Systems for Nutrition). 2016. Food Systems and Diets: Facing the Challenges of the 21st Century. London.

Golan, J, D. Headey, K. Hirvonen, \& J. Hoddinott. 2019. "ETHIOPIA, 2OOO-16." in The Oxford Handbook of the Ethiopian Economy, Edited by A. Oqubay \& F. Cheru. Oxford University Press.

Grace, D., S. Alonso, F. Mutua, K. Roesel, J.F. Lindahl, \& K. Amenu. 2018. "Food Safety Investment Expert Advice: Burkina Faso, Ethiopia, Nigeria." Nairobi, Kenya: International Livestock Research Institute (ILRI).

Guja, H., \& K. Baye. 2018. "Extrinsic Iron from Soil Contributes to Hb Regeneration of Anaemic Rats: Implications for Foods Contaminated with Soil Iron." British Journal of Nutrition 119 (8): 880-86.

Hawkes, C, \& J. Fanzo. 2017. "Nourishing the SDGs: Global Nutrition Report 2017."

Hawkes, C., M. T. Ruel, L. Salm, B. Sinclair, \& F. Branca. 2020. "Double-Duty Actions: Seizing Programme and Policy Opportunities to Address Malnutrition in All Its Forms." The Lancet 395 (10218), 142-55.

Headey, D., \& H.H. Alderman. 2019. "The Relative Caloric Prices of Healthy and Unhealthy Foods Differ Systematically across Income Levels and Continents." The Journal of Nutrition 149 (11): 2020-33. 
Headey, D., K.Hirvonen, \& J. Hoddinott. 2018. "Animal Sourced Foods and Child Stunting." American Journal of Agricultural Economics 100 (5): 1302-19.

Headey, D., J.Hoddinott, \& S. Park. 2017. "Accounting for Nutritional Changes in Six Success Stories: A RegressionDecomposition Approach." Global Food Security 13: 12-20.

Hirvonen, K, T.P. Sohnesen, \& T. Bundervoet. 2020. "Impact of Ethiopia's 2015 Drought on Child Undernutrition." World Development 131(2020) 104964.

Hirvonen, K. 2017. Improvements in Living Conditions in Ethiopia between 2000 and 2016: Evidence from Ethiopian Demographic and Health Survey Data. ESSP II Research Note 69. Washington, D.C. and Addis Ababa, Ethiopia: International Food Policy Research Institute (IFPRI) and Ethiopian Development Research Institute (EDRI).

Hirvonen, K, Y. Bai, D. Headey, \& W. A. Masters. 2020. "Affordability of the EAT-Lancet Reference Diet: A Global Analysis." The Lancet Global Health 8 (1): e59-66.

Hirvonen, K, \& D. Headey. 2018. "Can Governments Promote Homestead Gardening at Scale? Evidence from Ethiopia." Global Food Security 19: 40-47.

Hirvonen, K., J. Hoddinott, B. Minten, \& D. Stifel. 2017. "Children's Diets, Nutrition Knowledge, and Access to Markets." World Development 95: 303-15.

Hirvonen, K., A.S.Taffesse, \& I.W.Hassen. 2016. "Seasonality and Household Diets in Ethiopia." Public Health Nutrition 19 (10): 1723-30.

Hirvonen, K., \& A.Wolle. 2019a. Consumption, Production, Market Access and Affordability of Nutritious Foods in the Tigray Region of Ethiopia. Addis Ababa, Ethiopia: Alive \& Thrive; International Food Policy Research Institute (IFPRI).

Hirvonen, K., \& A.Wolle. 2019b. Consumption, production, market access and affordability of nutritious foods in the Afar Region of Ethiopia. Addis Ababa, Ethiopia: Alive \& Thrive; International Food Policy Research Institute (IFPRI).

Hirvonen, K., \& A.Wolle. 2019c. Consumption, production, market access and affordability of nutritious foods in the Amhara Region of Ethiopia. Addis Ababa, Ethiopia: Alive \& Thrive; International Food Policy Research Institute (IFPRI).

Hirvonen, K., \& A.Wolle. 2019d. Consumption, production, market access and affordability of nutritious foods in the Oromia Region of Ethiopia. Intl Food Policy Res Inst. Addis Ababa, Ethiopia: Alive \& Thrive; International Food Policy Research Institute (IFPRI).

Hirvonen, K., \& A.Wolle. 2019e. Consumption, production, market access and affordability of nutritious foods in the SNNP Region of Ethiopia. Addis Ababa, Ethiopia: Alive \& Thrive; International Food Policy Research Institute (IFPRI).

Hirvonen, K., \& A.Wolle. 2019f. Consumption, production, market access and affordability of nutritious foods in the Somali Region of Ethiopia. Addis Ababa, Ethiopia: Alive \& Thrive; International Food Policy Research Institute (IFPRI).

Hirvonen, K., A.Wolle, \& B.Minten. 2018. Affordability of Fruits and Vegetables in Ethiopia. ESSP II Research Note 70. Washington, DC and Addis Ababa, Ethiopia: International Food Policy Research Institute (IFPRI) and Ethiopian Development Research Institute (EDRI)..

Hoegh-Guldberg, O., D. Jacob, M.Taylor, M. Bindi, S. Brown, I. Camilloni, A. Diedhiou, R. Djalante, K. Ebi, \& F. Engelbrecht. 2018. "Impacts of 1.5 C Global Warming on Natural and Human Systems." In Global Warming of $1.5^{\circ}$ C.: An IPCC Special Report, 175-311. IPCC Secretariat.

IHME (Institute of Health Metrics and Evaluation). 2018. Findings from the global burden of disease study 2017. Seattle, WA.

IWMI (International Water Management Institute).2010. Irrigation potential in Ethiopia: constraints and opportunities for enhancing the system. Addis Ababa.

Kechero, F. K., K. Baye, A.T. Tefera, \& T. S. Tessema. 2019. "Bacteriological Quality of Commonly Consumed Fruit Juices and Vegetable Salads Sold in Some Fruit Juice Houses in Addis Ababa, Ethiopia." Journal of Food Safety 39(1), e12563.

Kim, S.S., P.H. Nguyen, L.M. Tran, S. Alayon, P. Menon, \& E.A. Frongillo. 2020. "Different Combinations of Behavior Change Interventions and Frequencies of Interpersonal Contacts Are Associated with Infant and Young Child Feeding Practices in Bangladesh, Ethiopia, and Vietnam." Current Developments in Nutrition 4 (2): nzz140.

Kim, S. S., P.H. Nguyen, Y. Yohannes, Y. Abebe, M.Tharaney, E.Drummond, E.A. Frongillo, M.T. Ruel, \& P. Menon. 2019. "Behavior Change Interventions Delivered through Interpersonal Communication, Agricultural Activities, Community Mobilization, and Mass Media Increase Complementary Feeding Practices and Reduce Child Stunting in Ethiopia." The Journal of Nutrition, 149(8), 1470-1481.

Kim, S.S., R. Rawat, E.M. Mwangi, R.Tesfaye, Y. Abebe, J. Baker, E.A. Frongillo, M.T. Ruel, \& P.Menon. 2016. "Exposure to Large-Scale Social and Behavior Change Communication Interventions Is Associated with Improvements in Infant and Young Child Feeding Practices in Ethiopia." PLOS ONE 11 (10). https://doi.org/10.1371/journal.pone.0164800.

Lemma, F., \& J.Matji. 2013. "Delivery Platforms for Sustained Nutrition in Ethiopia. Comment." Lancet 382 (9891), 488489. 
Madzorera, I., \& W. Fawzi. 2020. "Women Empowerment Is Central to Addressing the Double Burden of Malnutrition." EClinicalMedicine. 20 (100286) https://doi.org/10.1016/j.eclinm.2020.100286

Mangham-Jefferies, L., B.Mathewos, J. Russell, \& A. Bekele. 2014. "How Do Health Extension Workers in Ethiopia Allocate Their Time?" Human Resources for Health 12 (1): 61. https://doi.org/10.1186/1478-4491-12-61.

Melaku, Y.A., A.M. Temesgen, A. Deribew, G. A. Tessema, K. Deribe, B.W. Sahle, S.F. Abera, T.Bekele, F. Lemma, \& A.T. Amare. 2016. "The Impact of Dietary Risk Factors on the Burden of Non-Communicable Diseases in Ethiopia: Findings from the Global Burden of Disease Study 2013." International Journal of Behavioral Nutrition and Physical Activity 13 (1): 122.

Melesse, M.B., A.de Brauw, \& G.T. Abate. 2019. Understanding Urban Consumers' Food Choice Behavior in Ethiopia: Promoting Demand for Healthy Foods. ESSP Working Paper 131. Washington, DC and Addis Ababa, Ethiopia: International Food Policy Research Institute (IFPRI) and Ethiopian Development Research Institute (EDRI).

Minten, B., M.Dereje, F.N. Bachewe, \& S.Tamru. 2018. Evolving Food Systems in Ethiopia: Past, Present and Future. ESSP Working Paper 117. Washington, DC and Addis Ababa, Ethiopia: International Food Policy Research Institute (IFPRI) and Ethiopian Development Research Institute (EDRI).

Minten, B., Y. Habte, S. Tamru, \& A. Tesfaye. 2018. Transforming Agri-Food Systems in Ethiopia: Evidence from the Dairy Sector. ESSP Working Paper 129. Washington, DC and Addis Ababa, Ethiopia: International Food Policy Research Institute (IFPRI) and Ethiopian Development Research Institute (EDRI).

Minten, B., S. Tamru, \& T. Reardon. 2020. "Post-Harvest Losses in Rural-Urban Value Chains: Evidence from Ethiopia." Food Policy, 101860 https://doi.org/10.1016/j.foodpol.2020.101860

Misganaw, A., D. G. Mariam, A. Ali, \& T. Araya. 2014. "Epidemiology of Major Non-Communicable Diseases in Ethiopia: A Systematic Review." Journal of Health, Population, and Nutrition 32 (1): 1.

Misganaw, A., D. H. Mariam, A. Ali, \& T. Araya. 2014. "Epidemiology of major non-communicable diseases in Ethiopia: A systematic review." Journal of Health, Population, and Nutrition 32(1), 1.

Molla, B., R. Yilma, \& D. Alemayehu. 2004. "Listeria monocytogenes and other Listeria species in retail meat and milk products in Addis Ababa, Ethiopia." Ethiopian Journal of Health Development 18(3), 208-212.

Mwangome, M., \& A. M. Prentice. 2019. "Tackling the Triple Threats of Childhood Malnutrition." BMC Medicine 17, 210 (2019).

Passarelli, S., D. Mekonnen, E. Bryan, and C. Ringler. 2018. "Evaluating the Pathways from Small-Scale Irrigation to Dietary Diversity: Evidence from Ethiopia and Tanzania." Food Security 10 (4): 981-97.

Perez-Escamilla, R., O. Bermudez, G.S. Buccini, S. Kumanyika, C.K. Lutter, P. Monsivais, \& C. Victora. 2018. "Nutrition Disparities and the Global Burden of Malnutrition." British Medical Journal 361: k2252 doi: https://doi.org/10.1136/bmj.k2252

Popkin, B.M. 2017. "Relationship between Shifts in Food System Dynamics and Acceleration of the Global Nutrition Transition." Nutrition Reviews 75 (2): 73-82.

Popkin, B.M., L.S. Adair, \& S.W. Ng. 2012. "Global Nutrition Transition and the Pandemic of Obesity in Developing Countries." Nutrition Reviews 70 (1): 3-21.

Pradeilles, R., K. Baye, \& M. Holdsworth. 2019. "Addressing Malnutrition in Low-and Middle-Income Countries with Double-Duty Actions." Proceedings of the Nutrition Society 78 (3): 388-97.

Ruducha, J., C.Mann, N.S. Singh, T.D. Gemebo, N.S. Tessema, A. Baschieri, I. Friberg, et al. 2017. "How Ethiopia Achieved Millennium Development Goal 4 through Multisectoral Interventions: A Countdown to 2015 Case Study." The Lancet Global Health 5 (11): e1142-51. https://doi.org/10.1016/S2214-109X(17)30331-5.

Scott, P. 2017. "Global Panel on Agriculture and Food Systems for Nutrition: Food Systems and Diets: Facing the Challenges of the 21st Century."

Seyoum, Y., C. Humblot, G. Nicolas, M. Thomas, \& K. Baye. 2019. "Iron Deficiency and Anemia in Adolescent Girls Consuming Predominantly Plant-Based Diets in Rural Ethiopia." Scientific Reports 9 (1): 1-6.

Springmann, M., M. Clark, D.Mason-D'Croz, K.Wiebe, B.L.Bodirsky, L.Lassaletta, W.De Vries, S.J. Vermeulen, M. Herrero, \& K.M. Carlson. 2018. "Options for Keeping the Food System within Environmental Limits." Nature 562 (7728): 519-25.

Stuckler, D., M.McKee, S.Ebrahim, \& S.Basu. 2012. "Manufacturing Epidemics: The Role of Global Producers in Increased Consumption of Unhealthy Commodities Including Processed Foods, Alcohol, and Tobacco." PLoS Medicine 9 (6).

Tesfaye, G., D. Loxton, C. Chojenta, A. Semahegn, \& R. Smith. 2017. "Delayed Initiation of Antenatal Care and Associated Factors in Ethiopia: A Systematic Review and Meta-Analysis." Reproductive Health 14 (1): 150.

UNICEF. 1990. Strategy for Improved Nutrition of Children and Women in Developing Countries. New York.

UNICEF. 2019. UNICEF Global Databases: Infant and Young Child Feeding: Continued Breastfeeding. New York.

UN IGME (United Nations Inter-agency Group for Child Mortality Estimation). 2019. Levels and trends in child mortality: Report 2019. New York. 
Wehrmeister, F.C., M. Restrepo-Mendez, G. VA. Franca, C.G. Victora, \& A.JD. Barros. 2016. "Summary Indices for Monitoring Universal Coverage in Maternal and Child Health Care." Bulletin of the World Health Organization 94 (12): 903.

Wolle, A., K. Hirvonen, A. de Brauw, K. Baye, \& G.T. Abate. 2020. Household Food Consumption Patterns in Addis Ababa, Ethiopia. ESSP Working Paper 139. Washington, DC: International Food Policy Research Institute (IFPRI).

Worku, I.H., M. Dereje, B. Minten, \& K. Hirvonen. 2017. "Diet Transformation in Africa: The Case of Ethiopia." Agricultural Economics 48 (S1): 73-86.

WHO (World Health Organization). 2016. Accelerating Nutrition Improvements: Best Practices in Scaling up Nutrition Actions: Examples from Ethiopia, Uganda and the United Republic of Tanzania. Geneva.

WHO (World Health Organization). 2017. The Double Burden of Malnutrition. Policy Brief. Geneva.

Yaya, S., E.K. Odusina, O.A. Uthman, \& G.Bishwajit. 2020. "What Does Women's Empowerment Have to Do with Malnutrition in Sub-Saharan Africa? Evidence from Demographic and Health Surveys from 30 Countries." Global Health Research and Policy 5 (1): 1-11.

WHO/UNICEF JMP.2017. WHO/UNICEF joint monitoring programme for water supply and sanitation. https://washdata.org/. Accessed: April 2020.

Zerfu, T.A., E. Pinto, \& K. Baye. 2018. "Consumption of Dairy, Fruits and Dark Green Leafy Vegetables Is Associated with Lower Risk of Adverse Pregnancy Outcomes (APO): A Prospective Cohort Study in Rural Ethiopia." Nutrition \& Diabetes 8 (1): 52.

Zerfu, T.A., M. Umeta, \& K. Baye. 2016. "Dietary Diversity during Pregnancy Is Associated with Reduced Risk of Maternal Anemia, Preterm Delivery, and Low Birth Weight in a Prospective Cohort Study in Rural Ethiopia." The American Journal of Clinical Nutrition 103 (6): 1482-88.

Zerfu, T. A., M. Umeta, \& K. Baye. 2016. "Dietary Habits, Food Taboos, and Perceptions towards Weight Gain during Pregnancy in Arsi, Rural Central Ethiopia: A Qualitative Cross-Sectional Study." Journal of Health, Population and Nutrition 35 (22). 


\section{ABOUT THE AUTHORS}

Kaleab Baye is an Associate Professor in the Center for Food Science and Nutrition, Addis Ababa University, based in Addis Ababa, Ethiopia. Kalle Hirvonen is a Senior Research Fellow in the Development Strategy and Governance Division at the International Food Policy Research Institute (IFPRI), based in Addis Ababa, Ethiopia.

\section{ACKNOWLEGEMENTS}

We thank Anne Bossuyt, Bart Minten, Ferew Lemma, and Todd Benson for useful comments on the earlier versions of this report.

This publication has not been peer reviewed. Any opinions stated in this publication are those of the author(s) and are not necessarily representative of or endorsed by IFPRI.

INTERNATIONAL FOOD POLICY RESEARCH INSTITUTE

1201 Eye St, NW | Washington, DC 20005 USA

T. +1-202-862-5600 | F. +1-202-862-5606

Email: ifpri@cgiar.org | www.ifpri.org | www.ifpri.info

\section{IFPRI-ESSP ADDIS ABABA}

P.O. Box 5689, Addis Ababa, Ethiopia

T. +251-11-617-2000 | F. +251-11-667-6923

Email: ifpri-essp@cgiar.org | http://essp.ifpri.info
POLICY STUDIES INSTITUTE

P.O. Box 2479, Addis Ababa, Ethiopia

T. +251.11-550-6066; +251-11-553-8633 | F. +251-11-550-5588 http://psi.gov.et/

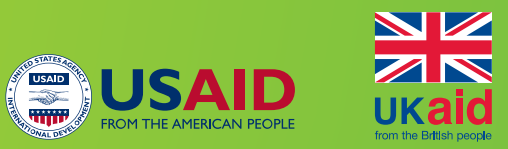

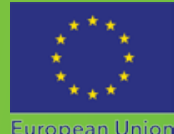

The Ethiopia Strategy Support Program (ESSP) is managed by the International Food Policy Research Institute (IFPRI); is jointly implemented with the Policy Studies Institute (PSI); and is financially supported by the United States Agency for International Development (USAID), the Department for International Development (DFID) of the government of the United Kingdom, and the European Union (EU).

This publication has been prepared as an output of ESSP and has not been independently peer reviewed. Any opinions expressed here belong to the author(s) and are not necessarily representative of or endorsed by IFPRI, PSI, USAID, DFID, or EU. 